\title{
Endoreplication: polyploidy with purpose
}

\author{
Hyun O. Lee, ${ }^{1}$ Jean M. Davidson, ${ }^{2}$ and Robert J. Duronio ${ }^{1,2,3,4,5}$ \\ ${ }^{1}$ Curriculum in Genetics and Molecular Biology, University of North Carolina, Chapel Hill, North Carolina 27599, USA; \\ ${ }^{2}$ Department of Biology, University of North Carolina, Chapel Hill, North Carolina 27599, USA; ${ }^{3}$ Program in Molecular Biology \\ and Biotechnology, University of North Carolina, Chapel Hill, North Carolina 27599, USA; ${ }^{4}$ Lineberger Comprehensive Cancer \\ Center, University of North Carolina, Chapel Hill, North Carolina 27599, USA
}

\begin{abstract}
A great many cell types are necessary for the myriad capabilities of complex, multicellular organisms. One interesting aspect of this diversity of cell type is that many cells in diploid organisms are polyploid. This is called endopolyploidy and arises from cell cycles that are often characterized as "variant," but in fact are widespread throughout nature. Endopolyploidy is essential for normal development and physiology in many different organisms. Here we review how both plants and animals use variations of the cell cycle, termed collectively as endoreplication, resulting in polyploid cells that support specific aspects of development. In addition, we discuss briefly how endoreplication occurs in response to certain physiological stresses, and how it may contribute to the development of cancer. Finally, we describe the molecular mechanisms that support the onset and progression of endoreplication.
\end{abstract}

\section{Endoreplication biology, conservation, and significance}

\section{Definition of endoreplication}

Endopolyploidy arises from variations of the canonical G1-S-G2-M cell cycle that replicate the genome without cell division. In this review, we use endoreplication as a general term encompassing any type of cell cycle leading to endopolyploidy. One widespread form of endoreplication is the developmentally controlled endocycle, which consists of discrete periods of S phase and G phase resulting in cells with a single polyploid nucleus (Edgar and Orr-Weaver 2001; Lilly and Duronio 2005). A key feature of the endocycle is that DNA content increases by clearly delineated genome doublings (Fig. 1). This is an important distinction from the aberrant process of rereplication, which is characterized by uncontrolled, continuous reinitiation of DNA synthesis within a given $S$ phase, resulting in increases in DNA content without clearly recognizable genome doublings (Fig. 1B; Blow and Hodgson 2002; Zhong et al. 2003). Rereplication

[Keywords: Endocycle; cell cycle; DNA replication; polyploid; development; cancer]

${ }^{5}$ Corresponding author.

E-MAIL duronio@med.unc.edu; FAX (919) 962-8472.

Article is online at http://www.genesdev.org/cgi/doi/10.1101/gad.1829209. results from perturbations to the molecular mechanisms that control the "once and only once" firing of replication origins during a normal diploid S phase, and is thought to be a source of genome instability that contributes to cancer.

Another major form of endoreplication occurs through the process of endomitosis, in which cells enter but do not complete mitosis (Fig. 1C). The best-studied example occurs in $64 \mathrm{~N}$ polyploid megakaryocytes (Ravid et al. 2002), which are responsible for producing the anucleated thrombocytes (or platelets) that mediate blood clotting (Ebbe 1976). Endomitosis is distinguished by the presence of early mitotic markers such as phospho-histone H3 (pH3), which marks condensed chromosomes (Hendzel et al. 1997). Endomitotic megakaryocytes reach metaphase or anaphase A, but never fully separate sister chromatids or undergo cytokinesis, resulting in globulated polyploid nuclei (Nagata et al. 1997; Vitrat et al. 1998). Endocycling cells, in contrast, do not display features of mitosis such as nuclear envelope breakdown, chromosome condensation, or $\mathrm{pH} 3$ staining. Thus, evolution has resulted in multiple mechanisms for achieving endopolyploidy. In the following sections, we describe some of the biological functions of endopolyploidy.

\section{Endoreplication is crucial for early development}

The evasion of controls that maintain diploidy may seem like a dangerous escapade for endoreplicating cells by opening up possibilities to upset genome integrity. However, endoreplication is an essential part of normal development. Many organisms employ endoreplication as part of terminal differentiation to provide nutrients and proteins needed to support the developing egg or embryo. Some of the best-studied examples include plant endosperm, Drosophila follicle and nurse cells, and rodent trophoblasts. The logical implication is that increasing DNA content by endoreplication is needed to sustain the mass production of proteins and high metabolic activity necessary for embryogenesis. Disrupting endoreplication in these cells often leads to embryonic lethality.

Developing plant seeds depend on endosperm tissue as an energy store before becoming self-sufficient through photosynthesis and root formation (Fig. 2A). Endosperm formation occurs soon after fertilization and is associated with a switch from a mitotic cell cycle to an endocycle 
Figure 1. Endoreplication. (A) Endocycles are defined as cell cycles consisting of S and G phase without cell division. Endocycling cells do not enter mitosis, and thus do not exhibit features of mitosis such as condensed chromosomes and nuclear envelope breakdown. Trichomes arise from polyploid cells that can be found on the surface of a variety of plant tissues. (The trichrome image was kindly provided by Dr. Sharon Regan, Department of Biology, Queen's University, Kingston, Ontario, Canada.) (B) Rereplication results from aberrant regulation in which DNA synthesis is initiated multiple times at individual origins of replication within a single $S$ phase. This results in an indistinct DNA content as depicted by black lines in this hypothetical FACS profile ( $Y$-axis is cell number and $X$-axis is DNA content). Green represents the diploid mitotic cell cycle profile, with $2 \mathrm{C}$ and $4 \mathrm{C}$ peaks. Red represents endoreplication cycles that result in distinct populations of cells with more than a 4C DNA content. $(C)$ During endomitosis, cells enter mitosis and begin to condense chromosomes, but do not segregate chromosomes to daughters. Instead, they enter a G1-like state and re-enter S phase. Megakaryocytes use endomitosis upon maturation, leading to a globulated nuclear structure. Blood clot-promoting thrombocytes (or platelets) bud off of the polyploid megakaryocytes. (Cell cycle cartoons are adapted by permission from Macmillan Publishers Ltd: Nature, Zhong et al. 2003 [๔ 2003].)

(Grafi and Larkins 1995; Leiva-Neto et al. 2004). This initiation of endocycles correlates with an increase in endosperm mass and rapid synthesis of starch (Schweizer et al. 1995), suggesting that by increasing the number of individual loci, endoreplication is able to assist in maximizing mRNA and protein synthesis. However, a 50\% reduction in the mean DNA content of polyploid maize endosperm cells had very little affect on the accumulation of starch and the accumulation of storage proteins and their mRNAs (Leiva-Neto et al. 2004). Leiva-Neto et al. (2004) therefore suggest that endosperm polyploidy may simply provide a mechanism to store nucleotides for use during embryogenesis and germination.

The importance of endoreplication in seed development is evident after exposure to environmental stress, such as high temperature or water deficit. In these resource-limited settings, the endosperm remains primarily mitotic, and reduction in the magnitude of endoreplication leads to a smaller endosperm, unfit to support the embryo (Engelen-Eigles et al. 2001). Another important polyploid cell type in early plant development is the suspensor cell (Fig. 2A). After fertilization, a plant zygote undergoes asymmetric division to give rise to the embryo and suspensor cell (Gilbert 2000). Suspensor cells employ endocycles to become polyploid, and provide nutrients to the embryo by bridging to the endosperm. Although a direct effect of suspensor endoreplication on embryogenesis is unknown, cultured scarlet beans with suspensor cells were twice as likely to survive as embryos without suspensor cells (Yeung and Meinke 1993).

In Drosophila melanogaster females, endoreplication is essential for the production of eggs. The highly polyploid, germline-derived nurse cells form an interconnected cyst that shares cytoplasm with the oocyte, and support oogenesis by synthesizing and transferring proteins and mRNA to the growing oocyte (Fig. 2B). This maternal supply of gene products is essential to direct the early stages of embryogenesis, which occur in the absence of zygotic transcription (Bastock and St Johnston 2008). Somatic follicle cells are also polyploid and envelop the developing oocyte to enable vitellogenesis and egg shell formation. Reduction of endoreplication in nurse and follicle cells causes sterility, supporting the idea that the endocycle plays a crucial role in oogenesis and early development (Lilly and Spradling 1996; Maines et al. 2004).

Because viviparous gestations do not require the same level of self-sufficiency as those of seeds or insect eggs, there is no mammalian tissue truly comparable with that of endosperm or nurse and follicle cells. In rodents, there is a specialized zygotic cell type that adopts the endocycle to promote placenta development and establish the interface between the embryo and the mother that supports embryogenesis (Zybina and Zybina 2005). Trophoblast giant cells (TGCs) are extraembryonic cells that facilitate uteral implantation of the fertilized egg and metastasis into maternal blood vessels to allow transport of nutrients, oxygen, and immunoglobins into the embryo (Fig. 2C; Cross 2000, 2005; Cross et al. 2002). TGCs differentiate from trophoectoderm that surrounds the early blastocyst. Differentiation is associated with rapid endocycling resulting in up to a 1000C DNA content (Cross 2000). TGC endoreplication is not used to directly provide gene products to the embryo, but increased gene expression through polyploidy may supply the energy necessary for aggressive invasion into the maternal tissue. In addition, a significant reduction in the magnitude 
A Plant embryo

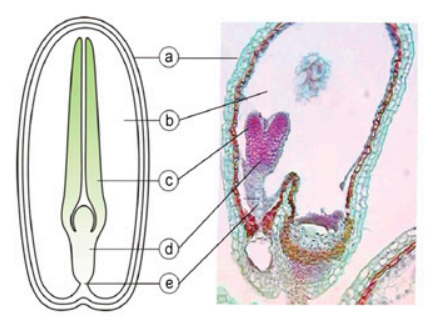

B Drosophila ovariole

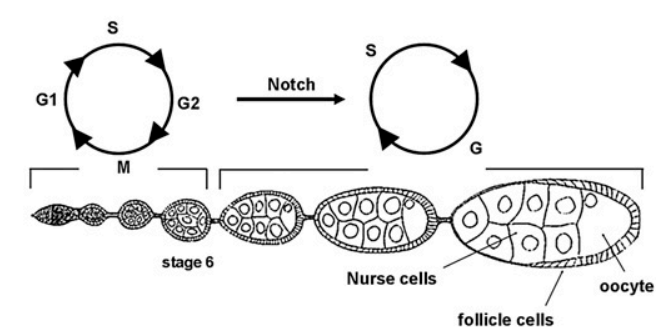

Trophoblast giant cells mediate implantation

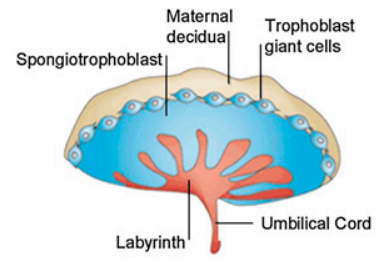

D Hypocotyl

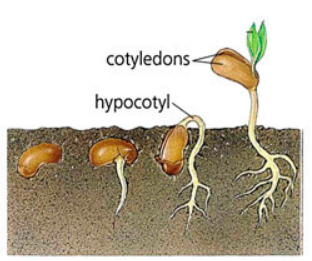

Figure 2. Examples of endocycling tissues. (A) A schematic and image of a section of a plant embryo. The seed coat (a) covers the endosperm (b), which surrounds and provides nutrients for the growing cotyledons (c) and hypocotyl (d) of the embryo. Suspensor cells (e) arise from asymmetric division of the fertilized egg and connect the embryo to the endosperm and are thought to be crucial in nutrient transfer. (Adapted from the Ohio State University at Lima Department of Biology, courtesy of Dr. Charles Good.) (B) Drosophila ovaries consist of 12-15 ovarioles (one is shown) containing a series of developing egg chambers. The germarium (far left) houses germline and somatic stem cells that differentiate into nurse cells plus oocyte and into follicle cells, respectively. Follicle cells switch to endocycles mid-oogenesis in response to Notch signaling, which down-regulates stimulators of mitosis such as string ${ }^{\text {cdc25 }}$ and acti-

vates inhibitors of mitosis like APC ${ }^{\mathrm{fzr} / \mathrm{cdh} 1} \cdot(C)$ Rodent TGCs are highly polyploid and facilitate embryo implantation by contributing to invasion into the uterine wall. (Adapted by permission from Macmillan Publishers Ltd: Nature Reviews Genetics, Rossant and Cross 2001 [@ 2001].) (D) The plant hypocotyl undergoes endocycles to rapidly grow above the ground. Once the young plant reaches the sun, hypocotyl endoreplication stops. (Adapted from Dictionary.com [The American Heritage Dictionary of the English Language, (C) 2000 by Houghton Mifflin Company.])

of endoreplication in TGCs causes embryonic lethality (Geng et al. 2003; Parisi et al. 2003; Garcia-Higuera et al. 2008). Restoration of endoreplication in these cells is sufficient to rescue embryonic viability, indicating that trophoblast endoreplication plays a crucial role in early mammalian development.

\section{Endoreplication supports the function of differentiated cells}

There are many examples of cells adopting endoreplication as part of terminal differentiation to support a specialized function. From plants to mammals, endoreplication is used to facilitate growth and to provide key functions to the adult organism, from nutrient uptake to defense. Perturbing endoreplication in these cells often causes organ malfunction and pathogenesis.

Endoreplication and growth. Organisms can grow via either an increase in cell number or an increase in cell size, or both. Since an increase in DNA content often correlates with increased cell size, endoreplication provides an efficient strategy for growth. For instance, producing the necessary surface area of cell membrane needed for several generations of cell division has been proposed to be slower and to require more energy than simply increasing the volume of a single cell (Kondorosi et al. 2000). Thus, in situations where energy sources are limiting or rapid growth is necessary, increasing cell volume without division may be more advantageous (Kondorosi et al. 2000). Endoreplication in plants most commonly occurs in tissues that develop mass quickly and have high metabolic activity (Inze and De Veylder 2006). One example of this occurs during early growth prior to photosynthesis, when the young hypocotyl emerges from the soil (Fig. 2D). This rapid growth is accomplished through endoreplication (Jakoby and Schnittger 2004). After emergence, this early developmentally controlled endoreplication subsequently becomes impacted by the environment, as endocycles are negatively regulated by sunlight (Gendreau et al. 1998). While different than the endopolyploidy we are discussing, it is interesting to note that the acquisition of a fully polyploid genome during the process of inbreeding or evolutionary selection may provide some plants with the advantage of a larger size and greater green mass over their diploid, subspecies counterparts (Ayala et al. 2000). Full genome polyploidy is commonly observed in cultivated plants such as coffee, watermelon, maize, potatoes, and bananas, among others. Finally, overall growth of Caenorhabditis elegans and Drosophila larvae is mainly driven by endoreplication (Edgar and Orr-Weaver 2001; Lozano et al. 2006). However, it is important to remember that endoreplication-associated growth is usually confined to specialized cell types that perform specific biological functions and is not a universal mechanism to control organism size. It has long been known that variations in mammalian body size are due to differences in cell number alone and not cell size. In fact, cells from mice and elephants have similar sizes (Wilson 1925).

The correlation between polyploidy and cell size raises the question of whether endoreplication per se triggers growth or whether growth promotes endoreplication. The answer is likely not a unidirectional cause-and-effect 
relationship, but rather a mutual feedback between growth and endoreplication: Organism growth can be mediated by, and depend on, an increase in cell size through endoreplication, while, conversely, inhibition of growth leads to reduction in endoreplication (Edgar and Nijhout 2004). Genetic perturbations in C. elegans that result in reduced body size are associated with reduced endoreplication of hypodermal cells (Flemming et al. 2000). Similarly, starvation in insects reduces endoreplication (Britton and Edgar 1998), and nutrient deprivation through inhibition of the insulin signaling pathway also blocks endoreplication (Britton et al. 2002). In addition, mutation of the Drosophila myc oncogene, which in flies acts to induce growth, causes a dramatic decrease in endoreplication in both somatic and germline cells of the ovary (Maines et al. 2004). Since Myc overexpression stimulates growth and could rescue the reduction in endoreplication imposed by inhibitors of insulin signaling, it was proposed that the endoreplication defect observed in Drosophila myc mutants is a secondary consequence of growth arrest (Pierce et al. 2004).

Endoreplication and nutrient utilization. Endoreplication is used extensively in tissues reserved for nutrient uptake and storage. Plant leaves and root hairs undergo endoreplication (Kondorosi et al. 2000), as do intestinal cells in Drosophila and C. elegans (Hedgecock and White 1985; Smith and Orr-Weaver 1991; Micchelli and Perrimon 2006; Ohlstein and Spradling 2006). Endoreplication in leaves and root hairs may aid in maximizing surface area to absorb light and water. However, whether polyploidy resulting from endoreplication is necessary for efficient or effective nutrient uptake has not been specifically addressed. Polyploid cells themselves can be used as an energy source. During metamorphosis, a Drosophila pupae is completely isolated from an exogenous food supply, and the biomass accumulated in polyploid cells during larval feeding is recycled for the differentiation and morphogenesis of adult tissues. Similarly, polyploid plant fruit tissue is used as energy for early plant development.

Endoreplication and functional tissue morphology. Endoreplication is also used by tissues that are needed to maintain organism homeostasis. Trichomes are specialized, branched cellular structures made by polyploid epidermal cells found on the aerial surface of many plant tissues (Fig. 1A). Trichomes can form irritable spines that work to deter herbivorous animals, keep frost away from other epidermal cells, or reflect ultraviolet radiation in exposed areas. They can also reduce the degree of evaporation by blocking the flow of air across the surface, or enhance the collection of rain and dew (Galbraith et al. 1991; Hulskamp et al. 1999|. Trichome structure is dependent on the degree of cellular polyploidy resulting from endoreplication. Mutation of the SIAMESE gene converts the normally unicellular trichomes of Arabidopsis into multicellular trichomes with reduced ploidy that sometimes have aberrant morphology (Walker et al. 2000). Thus, some tissues may grow via endoreplication because this avoids the cell shape changes associated with mitosis. The most recognized application of trichome structures is cotton fibers derived from the epidermal layer of the seed coat. These single cells differentiate through multiple rounds of endoreplication to become elongated "hair-like" structures. The extent and function of this elongation depends primarily on the plant's environment. In addition, plant root hairs allow the plants to become firmly rooted to the ground, and the lack of this structure leads to instability (Menand et al. 2007).

\section{Utilization of endoreplication for tissue regeneration after stress}

Endoreplication can be employed for growth and tissue regeneration during conditions that would otherwise prevent proliferation (Weigmann et al. 1997). By bypassing the controls that maintain genomic stability through diploidy, certain tissues react to exogenous stress by using endoreplication to grow and retain cell and organ function. There are clear examples of this in both plants and animals, indicating that a switch to endoreplication is a conserved method to maintain homeostasis despite dire conditions.

In Arabidopsis, there is a distinct correlation between response to environmental stresses and endocycle-dependent leaf area (Cookson et al. 2006). By overexpressing or mutating the gene encoding E2fe/DEL1, an atypical E2F transcription factor that acts to repress the endocycle (Vlieghe et al. 2005), Cookson et al. (2006) asked if the extent of endoreplication affected the plant's ability to respond to shade or water deficit stress. An increase in the extent of endoreduplication reduced the negative impact of water deficit on final leaf size. This suggests that adaptation via endopolyploidy can provide protection from stress and thus increase organism fitness, perhaps by maintaining tissues such as leaves that have a high photosynthetic capability. However, not all conditions were improved by endoreplication. The same study showed that increased endoreplication reduced the ability of leaves to achieve proper size in response to shade, likely because switching to an endocycle prevented the compensatory increase in cell number, and thus leaf expansion, via proliferation necessary to properly combat the reduced available light. Thus, depending on the signal and the situation, the most beneficial stress response can be achieved by endoreplication or cell proliferation.

A dramatic example of protective endoreplication in response to stress has been observed in animal cells (Lazzerini Denchi et al. 2006). In many tissues, telomere dysfunction (e.g., shortening or deprotecting) induces senescence or apoptosis (Hemann et al. 2001; Herbig et al. 2004). In contrast, hepatocytes in the liver do not apoptose in response to compromised telomeres that trigger a DNA damage response (Lazzerini Denchi et al. 2006). In addition, while loss of telomere integrity blocks hepatocyte cell division, these cells can nonetheless regenerate functional livers that were damaged by partial hepatecomy, and they do so via endoreplication. Thus, endoreplication can provide a means to achieve necessary growth in response to exogenous stress in a situation 
where compromised genome integrity precludes cell proliferation. Similar stress-induced switches to endoreplication have been observed in tumor tissues responding to genotoxic insults (Ivanov et al. 2003), in damaged cardiomyoctes (Meckert et al. 2005; Anatskaya and Vinogradov 2007), and in aging mouse hepatocytes (Funk-Keenan et al. 2008). Thus, it is interesting to speculate that stressinduced endoreplication is a general mechanism to achieve an increase in tissue mass and regain essential functions in response to compromised genomic integrity.

\section{Endoreplication as a default program upon mitotic catastrophe in both cancer and normal cells}

Endoreplication has been observed in cancer cells for many decades (Storchova and Pellman 2004). Early studies were aimed at understanding the mechanisms by which cancer cells became polyploid. Whether endoreplication is a causative agent in oncogenic transformation or progression is also not entirely clear. One possibility is that polyploidization is a precursor to aneuploidy that may contribute to oncogenesis (Fig. 3; Storchova and Pellman 2004). Another possibility is that cancer cells use endoreplication as a means of survival during mitotic catastrophe or genotoxic stress. For instance, some p53 mutant cancer cells undergo endoreplication rather than apoptosis upon treatment with anti-mitotic drugs such as colcemid and vinblastine (for review, see Erenpreisa et al. 2005a). This induces a form of endomitosis that appears for the most part to be a senescent situation. However, at low frequency some of these polyploid cancer cells can actually revert back into mitotic cell cycles via a process of genome reduction called depolyploidization (Prieur-Carrillo et al. 2003; Erenpreisa et al. 2005a,b; Puig et al. 2008). Human embryonic cells infected with SV-40 virus and subsequent inactivation of $\mathrm{p} 53$, and fibroblasts undergoing senescence, endoreplicate. These cells can also successfully depolyploidize (Walen 2002, $2007 \mathrm{a}, \mathrm{b})$.
Survival from anti-mitotic drug treatment by endoreplication and subsequent depolyploidization suggests a mechanism for how cancer cells become insensitive to anti-mitotic drugs. Could this also contribute to the recurrence of more aggressive cancers? Not only can endoreplication prolong the existence of cancer cells, it may also promote the selection of additional oncogenic mutations resulting from repeated rounds of replication in a cell that might have compromised the fidelity of DNA synthesis. Consequently, depolyploidization and re-entering the mitotic cycle after endoreplication could result in daughter cells with different genotypes, some of which might be highly cancerous.

What might be the mechanism of depolyploidization, which seems so counterintuitive? While the mechanism is unknown, some features of genome structure and organization in cells that undergo induced endoreplication (e.g., with mitotic spindle poisons) may be important. The genome is likely to be completely replicated during cancer cell endomitosis, and the nuclear packaging of the condensed, duplicated chromosomes may be advantageous in facilitating polyploid genomes to be separated during depolyploidization (Erenpreisa et al. 2005a,b). Curiously, cancer cells that undergo depolyploidization activate meiosis-specific genes (Erenpreisa et al. 2009; Ianzini et al. 2009), but how this might contribute to depolyploidization or if the depolyploidization process resembles in any way the reductional division of meiosis is not entirely clear (Erenpreisa et al. 2005a).

Other polyploid genomes display characteristic variations in organization and structure that likely preclude a return to mitotic proliferation. For example, unlike cancer cell endomitosis, the endocycles that generate polyploid cells during Drosophila development underreplicate the pericentric heterochromatin and thus do not duplicate the entire genome each endocycle S phase (Lilly and Duronio 2005). In addition, some cells organize their polyploid genome by aligning the multiple copies of sister chromatids along their lengths, leading to giant polytene

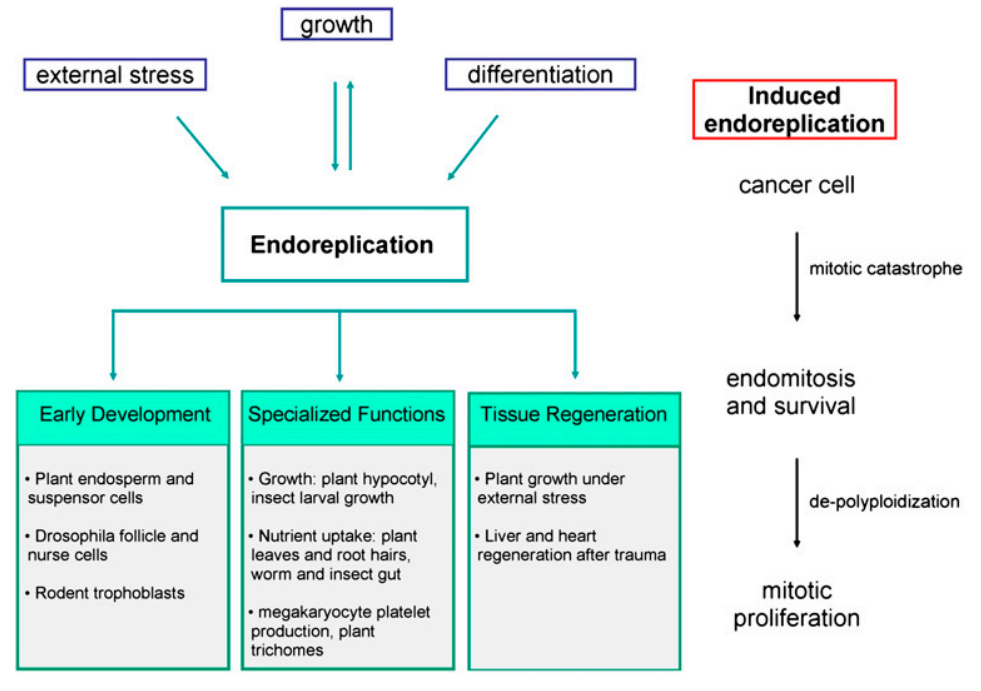

Figure 3. Examples of the endoreplication during normal and cancer development. 
chromosomes that contain a distinct banding pattern (Dej and Spradling 1999). This is perhaps most famous in the Drosophila salivary gland, but polytene chromosomes are also observed in plant ovules, leaves, and roots, and some tissues of the pollen sacs (Kondorosi and Kondorosi 2004). The functional significance of why a polyploid genome becomes polytene is not well understood. Nevertheless, polyteney coupled with incomplete replication of the whole genome, particularly centromeres, represents a terminally differentiated state that is not conducive to depolyploidization and a return to proliferative cycles. Polyploidy in differentiated cell types could also provide an advantage relative to diploid cells because the multiple gene copies may increase buffering against random, gene-inactivating mutations (e.g., by exogenous DNA-damaging agents).

Certain noncancerous cells can also be induced to undergo endoreplication upon mitotic stress, in contrast to most cells that arrest from mitotic checkpoints and/or undergo apoptosis. For more than 70 years, plant biologists have used colchicine to induce polyploidy (Eigsti 1938). Likewise, nocodazole treatment of keratinocytes also results in endoreplication (Gandarillas et al. 2000). Mammalian cells deficient of Fbw7, which encodes a component of a Cullin-RING E3 ubiquitin ligase (CRL) (Koepp et al. 2001; Strohmaier et al. 2001), were shown to induce endoreplication upon exposure to spindle toxins (Finkin et al. 2008). It will be interesting to determine whether the resumption of proliferation via depolyploidization in cells that undergo endomitosis-like endoreplication is used during normal development or part of normal tissue homeostasis. Intriguingly, depolyploidization has been noted recently in hepatocytes (Duncan et al. 2009).

\section{Transition into endoreplication}

Given that endoreplication is a crucial component of development and disease, an understanding of the molecular controls that govern the switch from mitotic cycles to endoreplication is important. In the following sections, we will examine some of the best-characterized examples of the developmental signals controlling the onset of endoreplication.

\section{Endocycles induced by Notch signaling}

During development, endocycling cells originate from proliferating diploid cells, which undergo conversion of the cell cycle as part of their program of differentiation. Studies of follicle cells in the Drosophila ovary have provided the most detailed paradigm for the developmental signals that regulate this type of cell cycle transition. Follicle cells are derived from somatic stem cells and proliferate to give rise to $\sim 650$ diploid cells encapsulating the germline cells (i.e., nurse cells and oocyte) (Fig. 2B; Bastock and St Johnston 2008). The mitosis-to-endocycle transition occurs midway through oogenesis and marks the beginning of the terminal differentiation of follicle cells. Subsequently, follicle cell endoreplication drives the production of proteins and mRNAs that support vitellogenesis and formation of the egg shell, or chorion.
Studies in the last decade have indicated that Notch signaling is a key regulator of the follicle cell mitotic-toendocycle transition. Notch is a transmembrane receptor that binds Delta or Serrate (Jagged in vertebrates) ligands, activating cleavage of Notch's intracellular domain, which enters the nucleus to regulate transcription of Notch-responsive genes (for reviews, see Gordon et al. 2008; Poellinger and Lendahl 2008; Talora et al. 2008). Notch mutant follicle cells do not switch to endocycles and continue to mitotically divide and express undifferentiated markers (Deng et al. 2001; Lopez-Schier and St Johnston 2001). Conversely, ectopic expression of Delta leads to precocious initiation of follicle cell endocycles (Jordan et al. 2006). Hedgehog (Hh) signaling antagonizes Notch by promoting the proliferation of follicle cells, and mutations in patched, a negative regulator of $\mathrm{Hh}$ signaling, lead to mitotic cycles at stages when endocycling normally occurs (Zhang and Kalderon 2000).

Recent studies have shed much light on the mechanisms by which Notch signaling promotes the transition into endocycles. In general, Notch promotes changes in gene expression resulting in the down-regulation of mitotic functions and the up-regulation activities needed for endoreplication. Notch signaling is known to modulate three important genes in this process: It induces expression of fizzy-related (fzr/Cdhl), an activator of the anaphase-promoting complex/cyclosome (APC/C) that triggers ubiquitin-mediated destruction of mitotic cyclins (Morgan 2007), and it represses expression of the S-phase cyclin-dependent kinase (CDK) inhibitor dacapo $\left(\right.$ dap $\left.^{\text {p21/p27 }}\right)$ and string ${ }^{\text {cdc25 }}$, a phosphatase that activates Cyclin/Cdk1 complexes needed for mitosis (Deng et al. 2001; Schaeffer et al. 2004; Shcherbata et al. 2004). These Notch-induced changes in gene expression are necessary. For instance, mutations affecting $f z r / C d h 1$ result in uncharacteristically small follicle cell nuclei due to a failure to switch into endocycles (Schaeffer et al. 2004). Likewise, mutation of Shaggy (sgg), the Drosophila GSK3 kinase, prevents Notch intracellular domain cleavage and a failure to both down-regulate string ${ }^{\text {cdc25 }}$ and express endocycling follicle cell markers (Jordan et al. 2006).

Several transcription factors respond to Notch signaling to control the mitotic-to-endocycle transition in follicle cells. Notch activates a transcription factor called Hindsight that mediates the down-regulation of the $\mathrm{Hh}$ pathway as well as the down-regulation of the homeodomain protein Cut, which is a repressor of $f z r / C d h 1$ expression (Sun and Deng 2005, 2007). Notch-mediated Hindsight expression is also crucial for down-regulating

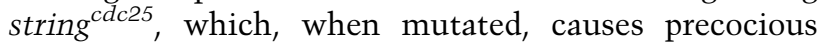
activation of endocycles (Sun and Deng 2005). Similarly, the absence of the zinc finger transcription factor tramtrack (ttk), a downstream target of Notch signaling, resulted in misregulation of string ${ }^{c d c 25}$, dap ${ }^{\text {21/p27, }}$, and $f z r / C d h 1$, causing a failure to transition into endocycles (Jordan et al. 2006). Thus, Notch signaling facilitates the mitotic-to-endocycle switch by regulating transcription factors that mediate the repression of genes needed for mitosis (e.g., string ${ }^{\text {cdc25}}$ ) and the activation of genes that stimulate destruction of mitotic regulators (e.g., $f z r / C d h 1)$. 
Whether the $f z r / C d h 1, d a p^{p 21 / p 27}$, or string ${ }^{c d c 25}$ genes are direct targets of these transcription factors is not known.

Interestingly, modulation of Notch signaling has also been implicated in the termination of follicle cell endocycles. In later stages of Drosophila oogenesis, follicle cells terminate endoreplication and undergo another transition in which genes needed for chorion formation become specifically amplified via reinitiation of origins of replication (Calvi and Spradling 1999; Claycomb et al. 2004; Tower 2004). Such gene amplification on top of endocycle-mediated polyploidization is needed to generate the gene copy number to support sufficient biosynthesis of proteins needed for eggshell production. Downregulation of Notch signaling plays a crucial role in conjunction with ecdysone hormone signaling to promote the switch from endocycles to gene amplification (Sun et al. 2008).

Notch signaling may contribute to the transition from mitotic to endocycles in mammals as well. More than a decade ago, tissue-specific Notch signaling factors were identified in TGCs and were proposed to down-regulate the Mash-2 transcription factor, a step that is necessary for giant cell differentiation (Nakayama et al. 1997). Targeted deletion in mice of the F-box protein Fbw 7 results in elevated levels of Notch signaling and an increased number of TGCs undergoing endoreplication (Tetzlaff et al. 2004). In addition, a requirement for Notch in megakaryocyte differentiation was described recently (Mercher et al. 2008).

\section{Hormone-induced endoreplication in plants and animals}

Plants provide many examples of developmentally regulated endoreplication. Because Notch signaling is not conserved in plants (Wigge and Weigel 2001), other signals must have evolved to regulate the onset and degree of endoreplication. Studies in plants as well as megakaryocytes in mammals suggest that hormonemediated pathways are also crucial for the transition to endoreplication.

Plants. Many genes that affect endoreplication in plant development have been identified through mutational studies (Sugimoto-Shirasu and Roberts 2003; Inze and De Veylder 2006). Interestingly, it appears that there are tissue-specific pathways that are responsible for endoreplication. The phytohormone gibberellin (GA) acts antagonistically to salicylic acid to initiate endocycles in trichomes and the hypocotyl (Collett et al. 2000; Joubes and Chevalier 2000). GA signals are mediated through GIS transcription factors and zinc finger protein 8 to upregulate the expression of GL1, a potent transcriptional activator of endocycles (Gendreau et al. 1999). Mutations in the GA pathway exhibit defects in endoreplication, leading to smaller or less-branched trichome structures and hypocotyl elongation (Gendreau et al. 1998, 1999). Spy is a negative regulator of GA, and its mutation causes overendoreplication phenotypes similar to wild-type plants treated with a high concentration of GA (Swain et al. 2002). In the roots, ethylene and auxin promote root hair formation and elongation. Thus, phytohormones are thought to mediate the fate determination of endocycling cells, as well as the magnitude of endoreplication. However, whether these signals actually initiate the transition into endocycles is not yet clear. It has been suggested that specific combinations of phytohormones, nutrients, and light trigger endoreplication (Kondorosi et al. 2000).

Megakaryocytes. Abnormal megakaryocyte function resulting in changes to the normal number of platelets is directly attributable to hematopoietic pathologies (Nurden 2005). Megakaryocyte ploidy is sometimes affected in patients with thrombocytopenia (low platelet counts) and thrombocytosis (high platelet counts), suggesting that endomitosis is important for efficient platelet formation (Tomer et al. 1989; Pang et al. 2005). However, the detailed mechanisms by which megakaryocyte ploidy is regulated are still not well understood.

Thrombopoietin (TPO) is a cytokine that stimulates differentiation of megakaryocyte progenitor cells by binding its receptor, c-Mpl (Kaushansky 2005, 2008). Injection of recombinant c-Mpl into normal mice increased platelet counts and megakaryopoiesis (Kaushansky et al. 1994). Recombinant TPO has been shown to induce megakaryocyte maturation and polyploidization in vitro (Kaushansky 1995). In addition, c-mpl or tpo mutations in mice or human patients exhibit reduced polyploidy of megakaryocytes and severe thrombocytopenia /Gurney et al. 1994; Alexander et al. 1996; Murone et al. 1998; Solar et al. 1998; Ihara et al. 1999).

TPO mediates proliferative signals largely through JAK/ STAT pathways (Drachman et al. 1999), while endomitosis signals seem to be mediated by ERK1/2 (Rojnuckarin et al. 1999). Megakaryocytes from mice expressing a truncated version of c-mpl did not efficiently activate ERK, leading to reduced endomitosis after TPO induction (Luoh et al. 2000). Although the mechanisms by which these signals are transduced are not well understood, evidence suggests that TPO-induced endomitosis also relies on similar downstream factors as Notch-induced endocycles. Differentiating megakaryocytes were shown to maintain high levels of the S-phase-promoting G1 cyclin Cyclin E (CycE), and ectopic expression of CycE could induce promegakaryocytes into endomitosis /Garcia and Cales 1996; Garcia et al. 2000). Studies of different megakaryoblastic cell lines suggest that endomitosis is promoted by the down-regulation of Cyclin B/Cdk1 mitotic kinase activity, similar to what occurs in Drosophila endocycles (Datta et al. 1996; Zhang et al. 1996; Kikuchi et al. 1997; Matsumura et al. 2000).

\section{The regulation of endocycle progression}

After the mitotic-to-endocycle transition, progression through the endocycle is coordinated by a subset of the same factors that control progression through mitotic cell cycles. These factors form a complex regulatory network 
that produce oscillations in the activity of Cdks that control DNA synthesis, resulting in alternating $S$ and $G$ phases leading to polyploidy.

\section{Replication origin control via oscillations of CycE/Cdk2 drive the endocycle}

To maintain genomic integrity, proliferating diploid cells must duplicate the entire genome once, and only once, per cell division cycle. This task is complicated by the fact that during $S$ phase, eukaryotic cells initiate DNA replication at many distinct sites in the genome (i.e., origins of replication). Highly conserved mechanisms exist to control origin initiation during $S$ phase and to prevent origin reinitiation and thus inappropriate rereplication of portions of the genome, within a given $S$ phase and the subsequent G2. This occurs through the regulated assembly of prereplicative complexes (pre-RCs) at each origin during G1 phase. The pre-RC is a multiprotein complex consisting of the hexameric origin recognition complex (ORC), Cdc6, and Cdc10-dependent transcript 1 (Cdt1). These proteins recruit the replicative DNA helicase, which is composed of the minichromosome maintenance 2-7 (MCM2-7) complex and the GINS complex (Labib and Gambus 2007). Once DNA synthesis is initiated at an origin, a variety of mechanisms that act on individual pre-RC proteins-including nuclear export, inactivating modification (e.g., phosphorylation), and ubiquitin-mediated degradation-prevent pre-RCs from reassembling until the next G1 (for review, see Arias and Walter 2007). Importantly, the current data suggest that, as with diploid cells, these same origin controls are operative during endocycles (Edgar and Orr-Weaver 2001).

Progression through both cell division cycles and endocycles is directed by periodic activation and inactivation of Cdks. The last 20 years of cell cycle research have revealed an elegant molecular paradigm for S-phase control in which a period of low Cdk activity (e.g., during G1) is permissive for pre-RC assembly, while a period of high Cdk activity (e.g., during S) both triggers the initiation of DNA synthesis and blocks the reassembly of preRCs. As a result, after the completion of $S$ phase, cells must sufficiently reduce Cdk activity to become competent for another round of DNA replication. In cell division cycles, this happens during mitosis when several mechanisms (e.g., cyclin destruction) lead to a period of low Cdk activity during G1. In endocycles, Cdk activity oscillates between high ( $\mathrm{S}$ phase) and low (G phase) to achieve the repeated rounds of DNA replication resulting in polyploidy.

In metazoan cell division cycles, activation of Cdk2 by G1 cyclins (e.g., CycE) drives entry into S phase, while activation of Cdk1 by M-phase cyclins (e.g., Cyclin B) promotes entry into and progression through mitosis (Morgan 2007). Mitotic Cdks are expressed at very low levels in endocycles (Narbonne-Reveau et al. 2008; Zielke et al. 2008), and endoreplication is driven by periodic activation/deactivation of S-phase Cdks (Follette et al. 1998; Weiss et al. 1998). In mammals, the Cdk requirement for $S$ phase, including endo $S$ phase, is provided redundantly between Cdk1 and Cdk2 (Aleem et al. 2005; Aleem and Kaldis 2006; Santamaria et al. 2007; Ullah et al. 2008), whereas in Drosophila Cdk2 is essential (Lane et al. 2000). CycE function is required for endoreplication in rodent trophoblasts and megakaryocytes (Geng et al. 2003; Parisi et al. 2003), and mutation of the single Drosophila CycE gene blocks DNA synthesis in both proliferating and endocycling cells (Knoblich et al. 1994). Thus, CycE/Cdk2 appears to be a major Cdk regulator of the endocycle in both insects and mammals (Fig. 4).

CycE/Cdk2 promotes DNA replication in several ways (Sclafani and Holzen 2007). For example, CycE expression can drive the chromatin loading of MCM proteins in Drosophila endocycling cells (Su and O'Farrell 1998), as it does in mitotic mammalian cells that are stimulated to leave quiescence by serum addition (Coverley et al. 2002; Geng et al. 2003). Importantly, CycE/Cdk2 can also direct dissociation of prereplication members from origins to inhibit reloading of the MCM helicase (Arias and Walter 2007). Thus, CycE/Cdk2 both triggers S phase and subsequently inhibits rereplication within $S$ phase. Consequently, a prevailing model of endocycle regulation is that periodic activation, or oscillation, of Cdk2 activity both promotes endocycle progression and ensures once and only once replication during each endocycle S phase. In support of this model, constitutive expression of $\mathrm{CycE}$ stalls endocycles in Drosophila salivary glands (Follette et al. 1998; Weiss et al. 1998). Interestingly, continuous CycE expression is permissive for mitotic cycles, as occurs naturally in early embryogenesis (Jackson et al. 1995; Sauer et al. 1995), and during gene amplification in Drosophila ovarian follicle cells (Calvi et al. 1998). These observations suggest that endocycle regulation is particularly dependent on oscillation in CycE/Cdk2 activity.

Figure 4. Regulation of the Drosophila endocycle. A complex array of controls ensures once and only once replication during endocycle progression. The key players are shown when they are active (green, solid lines) or inactive (red, dashed lines) in either the $G$ or $S$ phase of the endocycle. Control of $\mathrm{CycE} / \mathrm{Cdk} 2$ activity forms the core of endocycle regulation. CycE and CycE/
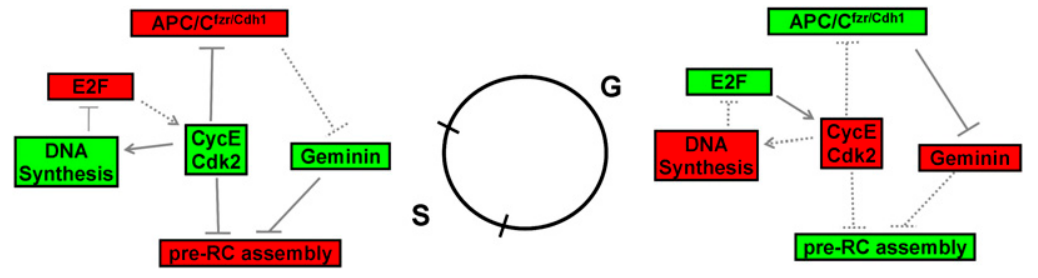
Cdk2 activity are low during G phase when APC/ $\mathrm{C}^{\mathrm{fzr} / \mathrm{cdh} 1}$ represses accumulation of Geminin, thereby allowing pre-RC formation. E2F stimulation of $C y c E$ transcription contributes to activation of $\mathrm{CycE} / \mathrm{Cdk} 2$ and the initiation of DNA replication, which triggers E2F1 destruction. CycE/Cdk2 directly represses pre-RC formation and inactivates APC/ $\mathrm{C}^{\mathrm{fzr} / \mathrm{cdh} 1}$, which allows Geminin accumulation that also inhibits pre-RC formation. 
How is the oscillation of CycE/Cdk2 activity during an endocycle achieved? There are both transcriptional and post-transcriptional inputs. In Drosophila endocycles, CycE abundance oscillates during endocycles, with peak levels in late G and S phase (Lilly and Spradling 1996). CycE gene expression in endocycling cells requires the E2F1 transcription factor (Duronio and O'Farrell 1995; Royzman et al. 1997; Duronio et al. 1998). We elaborate on this aspect of CycE regulation below. Studies in mammals and Drosophila revealed that a CRL of the SCF type is responsible for regulated CycE protein destruction (Koepp et al. 2001; Moberg et al. 2001; Strohmaier et al. 2001). Drosophila Archipelago (Ago; Fbw7 in mammals) is an F-box protein that acts as a substrate receptor for the SCF ubiquitin ligase by binding directly to CycE (Moberg et al. 2001). ago mutants fail to undergo endocycles in ovarian follicle cells, leading to small nuclei (Shcherbata et al. 2004). Similarly, mutation of minus, which likely encodes a novel substrate recognition subunit of SCF, results in hyperaccumulation of $\mathrm{CycE}$ and a block to endoreplication (Szuplewski et al. 2009). Thus, when $C y c E$ transcription is terminated in late endo $\mathrm{S}$ phase, CycE protein destruction likely contributes to a decline in $\mathrm{CycE} / \mathrm{Cdk} 2$ activity necessary for the period of low Cdk activity that is permissive for pre-RC assembly. CycE protein destruction may also contribute to mammalian endocycles. Fbw7-null mutant mice display elevated levels of CycE in trophoblasts, which display defects in endoreplication (Tetzlaff et al. 2004). Similarly, mice that lack Cullin1 activity exhibit elevated levels of $\mathrm{CycE}$ in trophoblasts, which fail to undergo endoreplication (Tateishi et al. 2001). However, these observations may be a result of CycE overexpression rather than changes in oscillations of $\mathrm{CycE}$ expression, since fluctuations of neither CycE protein nor mRNA were detected in trophoblasts (Geng et al. 2003).

This last observation suggests that additional regulators contribute to oscillations in $\mathrm{CycE} / \mathrm{Cdk} 2$ activity during endocycles. Likely candidates include Cdk inhibitors, or Ckis, which bind to and inhibit Cdk kinase activity (Morgan 2007). The level of the p57 Cki oscillates during rodent TGC endocycles (Hattori et al. 2000), with the greatest amount during G phase (Ullah et al. 2008). p57 activity was shown recently to promote endoreplication through down-regulating Cdk1 (Ullah et al. 2008). Similarly, expression of the Drosophila Cki Dacapo, which inhibits $\mathrm{CycE} / \mathrm{Cdk} 2$, oscillates in ovarian nurse cells (de Nooij et al. 2000). Furthermore, Dacapo expression in nurse cells is stimulated by $\mathrm{CycE}$, suggesting negative feedback regulation that may be important for endocycle progression (de Nooij et al. 2000). Mutation of dap disrupts nurse cell endoreplication, suggesting that Dap functions to enforce the period of low $\mathrm{CycE} / \mathrm{Cdk} 2$ activity needed for pre-RC assembly in this cell type (Hong et al. 2007).

The existence of multiple mechanisms that each contribute to oscillations in $\mathrm{CycE} / \mathrm{Cdk} 2$ activity creates the potential for variations in endocycle regulation in different cell types. Some evidence from Drosophila supports this idea. For example, ovarian nurse cell endocycles are disrupted in dap mutants (Hong et al. 2007), but both endocycling ovarian follicle cells and endocycling socket and shaft cells of mechanosensory bristles do not express dap, and thus likely do not require Dap function (Shcherbata et al. 2004; Audibert et al. 2005). In the salivary gland, transcriptional control of $C y c E$ expression appears to be more important than in nurse cells, where CycE protein levels oscillate (Lilly and Spradling 1996) but CycE mRNA levels do not (Royzman et al. 2002). Multiple mechanisms of $\mathrm{CycE} / \mathrm{Cdk} 2$ control lead to increased robustness of endocycle progression and provide an opportunity for multiple regulatory inputs that may be differentially used in different cell types.

\section{Ubiquitin-mediated proteolysis promotes endocycle progression}

Ubiquitin-mediated proteolysis plays an important role in both endocycle initiation and progression (Ullah et al. 2009). The key regulator is the APC/C, an E3 ubiquitin ligase best known for its role in targeting proteins (e.g., cyclins) for destruction during mitosis (Morgan 2007). To target specific proteins for ubiquitination and destruction, the APC/C interacts with two proteins, fzy/Cdc20 and $\mathrm{fzr} / \mathrm{Cdh} 1$, which function as activators for the $\mathrm{APC}$ at different points in the cell cycle. $\mathrm{APC} / \mathrm{C}^{\mathrm{fzy} / \mathrm{Cdc} 20}$ is active only during mitosis and triggers the metaphase-toanaphase transition, while APC/ $\mathrm{C}^{\mathrm{fzr} / \mathrm{Cdh} 1}$ is active from the metaphase/anaphase transition through the subsequent G1. One of the functions of APC/ $\mathrm{C}^{\mathrm{fzr} / \mathrm{Cdh} 1}$ is to prevent mitotic cyclin accumulation during G1. This helps maintain a period of low CDK activity necessary for pre-RC formation. This function is important for the mitotic-toendocycle transition, as first shown in Drosophila $\mathrm{fzr} /$ Cdh1 mutant embryos, which inappropriately accumulate mitotic cyclins and fail to enter endocycles (Sigrist and Lehner 1997). As discussed above, Notch signaling induces $\mathrm{fzr} / \mathrm{Cdh} 1$ expression during the mitotic-to-endocycle transition in Drosophila follicle cells. Similarly, genetic inhibition of a plant ortholog of fzr/Cdh1, ccs52, results in inhibition of endocycles (Cebolla et al. 1999), and mutation of mouse $f z r$ blocks TGC endoreplication (Garcia-Higuera et al. 2008), suggesting that APC/C $\mathrm{C}^{\mathrm{fzr} / \mathrm{Cdh} 1}$ involvement in the mitotic-to-endocycle transition is an evolutionarily ancient mechanism. However, from these data it was unclear whether APC/C activity is needed during endocycle progression.

Recent reports from two groups revealed that APC/C activity is necessary to sustain endocycle progression in Drosophila, in part by targeting the Geminin protein for destruction (Narbonne-Reveau et al. 2008; Zielke et al. 2008). Geminin is an inhibitor of DNA replication, and acts by binding directly to Cdt 1 and preventing Cdt 1 from recruiting the MCM2-7 helicase to origins (Wohlschlegel et al. 2000). In mitotic cycles, Geminin is targeted for destruction by APC/C at the metaphase-anaphase transition, and does not reaccumulate until late G1 when APC/C is inactivated by G1 Cyclin/Cdk-mediated phosphorylation of Cdh1 (McGarry and Kirschner 1998; Zachariae et al. 1998). Genetic depletion of APC/C 
components in Drosophila follicle cells and salivary glands results in Geminin hyperaccumulation and disrupts endocycle progression, likely because pre-RC formation is inhibited (Narbonne-Reveau et al. 2008; Zielke et al. 2008). Conversely, mutation of Geminin causes defects during very early mouse embryogenesis that are consistent with either inappropriate endoreplication or rereplication (Gonzalez et al. 2006; Hara et al. 2006).

Geminin protein accumulation oscillates in unperturbed Drosophila endocycles, with high levels occurring during $S$ phase and low levels occurring during $G$ phase (Zielke et al. 2008). This cyclic expression could help constrain Cdt1 activity to $\mathrm{G}$ phase when pre-RCs are formed, and thus may prevent rereplication during endo $S$ phase. How is cyclic Geminin accumulation achieved? By monitoring the levels of the APC/C target Orc1, Narbonne-Reveau et al. (2008) show that APC/C activity also oscillates in endocycles. They and Zielke et al. (2008) suggest that $\mathrm{CycE} / \mathrm{Cdk} 2$ promotes the phosphorylation and inhibition of $\mathrm{fzr} / \mathrm{Cdh} 1$, which prevents the APC/C from acting on its targets, resulting in accumulation of Geminin during $S$ phase. The model that emerges is that $\mathrm{APC} / \mathrm{C}^{\mathrm{fzr} / \mathrm{Cdh} 1}$ plays a critical role in the $\mathrm{G}$ phase of an endocycle by stimulating pre-RC assembly in two ways: (1) targeting the Cdt1 inhibitor Geminin for destruction, and (2) maintaining low levels of mitotic CDK activity. In this way APC/ $\mathrm{C}^{\mathrm{fzr} / \mathrm{Cdh} 1}$ acts much like it does during G1 phase of a mitotic cycle, suggesting that endocycles are essentially G1-S cycles. Moreover, cycles of APC/C $C^{\mathrm{fzr} / \mathrm{Cdh} 1}$ activity are directly, and inversely, tied to cycles of CycE/ Cdk2 activity, thus forming a key component of the endocycle regulatory circuit (Fig. 4).

While inappropriate Geminin hyperaccumulation may be sufficient to block endocycles, there are likely other targets of the $\mathrm{APC} / \mathrm{C}^{\mathrm{fzr} / \mathrm{Cdh} 1}$ that must be kept low for normal endocycle progression to occur. For instance, in Drosophila salivary glands, preventing Geminin accumulation does not relieve the block to endoreplication in conditions where $\mathrm{APC} / \mathrm{C}^{\mathrm{fzr} / \mathrm{Cdh} 1}$ is held inactive by overexpression of CycE (Narbonne-Reveau et al. 2008). Mitotic cyclins are targets of $\mathrm{APC} / \mathrm{C}^{\mathrm{fzr} / \mathrm{Cdh} 1}$, and Cyclin A (CycA) activity can suppress endocycles in both flies and plants (Sauer et al. 1995; Hayashi 1996; Imai et al. 2006). Thus, in the absence of APC/C ${ }^{\mathrm{fzr} / \mathrm{Cdh} 1}$ activity, the inappropriate accumulation of CycA, even in cells with very little CycA mRNA (Zielke et al. 2008), could also contribute to endocycle arrest by ectopically activating CycA-dependent Cdks and inhibiting pre-RC assembly.

\section{Transcriptional control of the endocycle}

As noted above, transcriptional controls via a variety of factors play an important role in endoreplication. Some of these factors affect the activity of CycE/Cdk2, and thus contribute to the core endocycle mechanism, while others regulate the transition into endocycles and/or contribute to the differentiated state that is permissive for endoreplication.

Modulation of endocycle progression by E2F. The E2F family of transcription factors regulates the G1-S transi- tion in both mitotic and endocycling cells by controlling genes encoding factors necessary for DNA synthesis and S-phase progression (Dimova and Dyson 2005; DeGregori and Johnson 2006; van den Heuvel and Dyson 2008). The E2F family is composed of positive and negative regulators of transcription, and both types play a role in endocycle progression in animals and plants (Duronio et al. 1998; Boudolf et al. 2004). In Drosophila E2f1 mutants, DNA synthesis and endocycle progression is drastically attenuated (Duronio et al. 1995, 1998; Royzman et al. 1997), similar to observations made in TGCs in a mouse mutant of DP1, the obligate binding partner of E2F (Kohn et al. 2003). Therefore, at least some E2F transcriptional targets must be important for endocycle progression, even though recent reports indicate that in Drosophila these targets are expressed at lower levels than in mitotic cells (Zielke et al. 2008; B Calvi, pers. comm.). Drosophila $\mathrm{E} 2 \mathrm{f} 1 / \mathrm{Dp}$ is required for the expression of a host of replication factors during endoreplication. However, the key E2f1 target is the CycE gene, whose expression both oscillates and requires E2f1 and Dp during Drosophila endocycle progression (Duronio and O'Farrell 1995; Duronio et al. 1995, 1998; Royzman et al. 1997). Interestingly, Drosophila CycE also negatively regulates its own expression by down-regulating E2f1 activity (Duronio et al. 1995; Sauer et al. 1995). These data suggest a model whereby E2F-directed transcriptional regulation of $C y c E$ contributes to the oscillations of $\mathrm{CycE} / \mathrm{Cdk} 2$ activity that are critical for endocycle progression (Fig. 4).

How might cycles of E2f1 activation and inhibition occur? Very recent work has provided new insight into the mechanism. The most well-studied mode of E2F regulation is via E2F interaction with the retinoblastoma family of tumor suppressor proteins, which are conserved in both insects and plants (Inze and De Veylder 2006; van den Heuvel and Dyson 2008). pRb family proteins bind and inhibit E2F during periods of low CDK activity (i.e., G1). However, mutations in Drosophila Rbf1, which binds and inhibits E2f1, do not affect endocycle progression (Du et al. 1996; Du and Dyson 1999; Du 2000), suggesting the possibility for a pRb-independent mode of regulation. Like its transcriptional targets and other regulators that we discussed, E2f1 protein accumulation oscillates during endocycles, with high levels during G phase and low levels during $S$ phase (Zielke et al. 2008). We demonstrated recently that E2f1 is targeted for destruction in replicating cells by a mechanism requiring a motif in the E2f1 protein called a PIP box (Shibutani et al. 2008), which interacts with PCNA bound to chromatin at replication forks (Arias and Walter 2006; Higa et al. 2006; Hu and Xiong 2006; Senga et al. 2006; Havens and Walter 2009). This interaction recruits a Cul4 ${ }^{\mathrm{Cdt} 2}$ E3 ubiquitin ligase that targets E2f1 for destruction (Shibutani et al. 2008). This suggests a model in which accumulation of E2f1 during $\mathrm{G}$ phase drives $C y c E$ transcription, which activates Cdk2 and triggers entry into $S$ phase and the subsequent destruction and inactivation of E2f1 (Edgar and Nijhout 2004). The resulting down-regulation of $C y c E$ transcription and destruction of CycE protein (described above) create the period of low 
CDK activity in the following $G$ phase where origins are assembled in preparation for the next cycle. A predication of this model is that blocking S-phase-coupled E2f1 destruction will attenuate endocycle progression. Indeed, expressing a mutant version of E2f1 lacking a functional PIP box results in continuous CycE expression and blocks the endocycle in larval salivary glands (BA Edgar, pers. comm.). Interestingly, the same E2f1 mutant does not block cell proliferation, even though E2f1 protein is destroyed during $S$ phase in cell division cycles (Shibutani et al. 2008). This again illustrates that endocycles and cell division cycles contain common modes of regulation, but depend differently on these forms of regulation for cell cycle progression. In addition, because robust oscillations of $\mathrm{CycE}$ transcription are not observed in ovarian nurse cells (Royzman et al. 2002), it will be interesting and important to determine if S-phase-coupled E2f1 destruction is important in all endocycles.

Modulation of endocycle progression by repressor E2Fs. Plants also contain $\mathrm{pRb}$ and both repressor and activator E2Fs. Tobacco $\mathrm{pRb}$ function modulates the extent of endoreplication, as disruption of $\mathrm{pRb}$ resulted in increased endoreplication (Park et al. 2005). Similarly, functional reduction of the Arabidopsis E2fc/DPB repressor results in higher proliferation activity, yet a severe reduction in organ size because cells are unable to switch to endoreplication-mediated growth (del Pozo et al. 2006). Thus, pRb/E2F pathways regulate a balance between proliferation and endoreduplication during development that is a critical feature of plant growth and final organ size. In Drosophila, the absence of the E2f1 activator results in the E2f2 repressor acting to inhibit proliferation, likely by repressing cell cycle targets of E2f1 (Frolov et al. 2001; Rasheva et al. 2006). E2f2 mutant salivary gland cells have reduced ploidy, and in the absence of both E2f1 and E2f2, some endocycles are inhibited because of elevated, continuous expression of $\mathrm{CycE}$ (Weng et al. 2003).

A recently described family of atypical E2F repressors plays an important role in endocycle initiation in plants. These E2F repressors are also found in animals, and contain two DNA-binding domains, do not bind to DP, and lack an obvious $\mathrm{pRb}$ interaction domain (Lammens et al. 2009). E2fe/DEL1 is an Arabidopsis atypical E2F expressed in mitotically active cells that controls the timing of endocycle onset by repressing the expression of a homolog of $\mathrm{fzr} / \mathrm{Cdh} 1$ (called CCS52A2) (Vlieghe et al. 2005; Lammens et al. 2008). As in Drosophila, Arabidopsis $\mathrm{APC} / \mathrm{C}^{\mathrm{fzr} / \mathrm{Cdh} 1}$ triggers endocycle onset by triggering the destruction of mitotic cyclins and the consequent inhibition of mitotic CDK activity (Boudolf et al. 2009). Such regulation may be conserved in mammals, since human E2f7 associates with the promoter of the Cdh1 gene (Lammens et al. 2008).

Other transcriptional inputs into endoreplication. Transcription factors other than E2F have been implicated in the initiation and maintenance of endocycles. Drosophila mutants of the zinc finger transcription factor escargot (esg) display ectopic entry into the endocycle in normally diploid larval histoblasts (Hayashi et al. 1993). Ectopic Esg expression can also block endoreplication (Fuse et al. 1994). Esg acts to maintain the activity of Cdk1, which when inactivated can trigger endoreplication in normally diploid cells (Hayashi 1996; Weigmann et al. 1997). Similarly, mSna, a murine homolog of Esg, acts to repress the mitotic-to-endocycle transition of TGCs (Nakayama et al. 1998). In addition, constitutive ectopic expression of Esg inhibits megakaryocyte endomitosis (Ballester et al. 2001). The basic helix-loop-helix (bHLH) transcription factor superfamily member Hand1 promotes TGC differentiation and endoreplication, but the mechanism by which Hand1 (e.g., via transcriptional targets) acts is not known (Martindill and Riley 2008).

\section{Endocycle-specific regulation}

We have been emphasizing similarities in replication control between mitotic cycles and endocycles. As more and more is learned about endocycle regulation, these similarities of molecular mechanism may seem obvious in retrospect, as completely new mechanisms for fundamental cell biological processes like DNA replication typically do not arise during evolution. However, recent data have provided hints that there may indeed be endocycle-specific regulatory mechanisms, or at least modifications of core regulation that support specific aspects of the biology of endocycling cells.

Endocycle modulation of pre- $R C$ assembly. Endoreplicating cells in plants and animals control and respond to the expression of pre-RC components differently than in proliferating cells. Arabidopsis contains two ORC1 genes that are targets of E2F and that show peaks of expression as cells enter $\mathrm{S}$ phase. One of these two ORC1 genes is preferentially expressed in endocycling tissues (Diaz-Trivino et al. 2005). Similarly, human CDC6 contains an endocycle-specific cis-regulatory element that binds to Esg (Vilaboa et al. 2004). Pre-RC components are more stable in endoreduplicating plant cells and megakaryocytes (Castellano et al. 2001; Bermejo et al. 2002).

A recent report raised the possibility that regulation of pre-RC assembly may be different in endocycling cells (Park and Asano 2008). Drosophila orc1 mutants survive through larval development, and the highly polyploid salivary glands of these mutants were indistinguishable from wild type. As Orc1 is a critical component of preRCs and is essential for DNA replication in other contexts (Bell and Dutta 2002), one possibility is that the maternally derived Orc1 protein is sufficient to support DNA replication during larval growth, as suggested by genetic studies of other Drosophila Orc subunits (Pinto et al. 1999; Pflumm and Botchan 2001). Interestingly, Park and Asano (2008) could not detect Orcl protein in orc1 mutant salivary glands and concluded that Drosophila Orc1 is dispensable for endoreplication. This is particularly surprising because Orcl is required for cell proliferation and for gene amplification in follicle cells 
(Park and Asano 2008). Moreover, other components of the pre-RC such as Cdt1 are required for endoreplication (Park and Asano 2008). Because Drosophila Orcl is degraded at mitosis by the APC/C (Araki et al. 2003, 2005), presumably including the last mitosis before the onset of endocycles, there should be no Orc1 present when salivary gland cells transition to the endocycle during embryogenesis. However, embryonic salivary gland cells enter the first endoreplication S phase from G2 (Smith and Orr-Weaver 1991), suggesting that a small amount of Orcl synthesized during interphase from maternal transcript could be present in orc1 mutant salivary gland cells. However, this interpretation demands that an amount of Orc1 below detection by molecular and microscopic methods is sufficient to support genome duplication to the level of $1000 \mathrm{C}$ over the course of larval development. Another possibility is that Orcl function in the salivary gland is provided by another of the Orc subunits. A discussion of possible Orc-independent endoreplication can be found in Asano (2009).

Endocycle modulation of the DNA damage response. In endocycling cells, $\mathrm{S}$ phase is often terminated before the entire genome has been duplicated (Smith and Orr-Weaver 1991). In Drosophila polyploid cells, pericentric heterochromatin is often underreplicated (Lilly and Spradling 1996; Leach et al. 2000). After repeated endocycles, this results in many stalled replication forks that trigger a DNA damage response. This damage occurs in or near the underreplicated heterochromatin where replication forks presumably stall (Hong et al. 2007; Mehrotra et al. 2008). Mitotic cells respond to damage resulting from stalled replication forks by either arresting the cell cycle or inducing apoptosis, but endocycling cells do neither. How does the cell differentiate between the type of cycle used and the level of sensitivity to unreplicated, or damaged, DNA? Mehrotra et al. (2008) probed this question by inducing rereplication-mediated DNA damage with overexpression of Cdt1. In diploid cells, this treatment triggers apoptosis via p53-dependent and p53-independent pathways. However, despite the accumulation of DNA damage in endocycling cells in response to Cdt1 overexpression, there was no evidence of induction of apoptosis. While endocycling cells can still respond to proapoptotic genes and enter apoptosis, they have a muted response to p53 activation and express proapoptotic genes at a lower level than cycling diploid cells (Mehrotra et al. 2008). Similarly, DNA damage induced by chromatin assembly factor-1 (CAF-1) depletion does not adversely affect endocycle progression (Klapholz et al. 2009). Thus, polyploid cells have evolved a mechanism to buffer against the DNA damage that accumulates during normal endocycle progression.

A similar situation exists in mammals. In the process of trophoblast stem cells differentiating into endocycling TGCs, p57 expression in response to FGF4 deprivation initiates the transition to endocycles by inhibiting Cdk1, which is required to enter mitosis, while the Cki p21 suppresses expression of the checkpoint protein kinase Chk1 (Ullah et al. 2008). p21 is not required for endocycle initiation, but instead is needed to suppress the DNA damage response. Thus, this combination of regulation induces the transition into endocycles while preventing the normal cell cycle checkpoint machinery from detecting endoreplication as detrimental DNA damage.

\section{Summary}

Recent research has provided new insight into the mechanisms of endoreplication and the function of polyploidization. Endoreplication is generally controlled by the same cell cycle regulators that drive the cell division cycle, particularly those that control the G1-S transition and subsequent DNA synthesis. Importantly, endoreplication is highly conserved in evolution and is employed as a form of growth by multiple cell types that perform specialized functions during the development of many plant and animal species. In each of these species, the magnitude of polyploidization varies from one cell type to another, but little is known about how this variation is achieved or what function it might serve. More recently, there is increasing appreciation for how endoreplication and polyploidy contribute to stress response and pathogenesis, but much remains to be learned in this regard. Our increasing knowledge of, and ability to manipulate, cell cycle progression should provide the tools to address these interesting questions.

\section{Acknowledgments}

We thank Norman Zielke, Duronio laboratory members, and the anonymous reviewers for corrections and helpful comments that improved the manuscript. This work was supported by NIH grant GM57859.

\section{References}

Aleem E, Kaldis P. 2006. Mouse models of cell cycle regulators: New paradigms. Results Probl Cell Differ 42: 271-328.

Aleem E, Kiyokawa H, Kaldis P. 2005. Cdc2-cyclin E complexes regulate the G1/S phase transition. Nat Cell Biol 7: 831-836.

Alexander WS, Roberts AW, Nicola NA, Li R, Metcalf D. 1996. Deficiencies in progenitor cells of multiple hematopoietic lineages and defective megakaryocytopoiesis in mice lacking the thrombopoietic receptor c-Mpl. Blood 87: 2162-2170.

Anatskaya OV, Vinogradov AE. 2007. Genome multiplication as adaptation to tissue survival: Evidence from gene expression in mammalian heart and liver. Genomics 89: 70-80.

Araki M, Wharton RP, Tang Z, Yu H, Asano M. 2003. Degradation of origin recognition complex large subunit by the anaphase-promoting complex in Drosophila. EMBO I 22: 6115-6126.

Araki M, Yu H, Asano M. 2005. A novel motif governs APCdependent degradation of Drosophila ORC1 in vivo. Genes \& Dev 19: 2458-2465.

Arias EE, Walter JC. 2006. PCNA functions as a molecular platform to trigger Cdt1 destruction and prevent re-replication. Nat Cell Biol 8: 84-90.

Arias EE, Walter JC. 2007. Strength in numbers: Preventing rereplication via multiple mechanisms in eukaryotic cells. Genes \& Dev 21: 497-518. 
Asano M. 2009. Endoreplication: The advantage to initiating DNA replication without the ORC? Fly (Austin) 3: 173-175.

Audibert A, Simon F, Gho M. 2005. Cell cycle diversity involves differential regulation of Cyclin E activity in the Drosophila bristle cell lineage. Development 132: 2287-2297.

Ayala FJ, Fitch WM, Clegg MT. 2000. Variation and evolution in plants and microorganisms: Toward a new synthesis 50 years after Stebbins. Proc Nat1 Acad Sci 97: 6941-6944.

Ballester A, Frampton J, Vilaboa N, Cales C. 2001. Heterologous expression of the transcriptional regulator escargot inhibits megakaryocytic endomitosis. J Biol Chem 276: 43413-43418.

Bastock R, St Johnston D. 2008. Drosophila oogenesis. Curr Biol 18: R1082-R1087. doi: 10.1016/j.cub.2008.09.011.

Bell SP, Dutta A. 2002. DNA replication in eukaryotic cells. Annu Rev Biochem 71: 333-374.

Bermejo R, Vilaboa N, Cales C. 2002. Regulation of CDC6, geminin, and CDT1 in human cells that undergo polyploidization. Mol Biol Cell 13: 3989-4000.

Blow JJ, Hodgson B. 2002. Replication licensing-Defining the proliferative state? Trends Cell Biol 12: 72-78.

Boudolf V, Vlieghe K, Beemster GT, Magyar Z, Torres Acosta JA, Maes S, Van Der Schueren E, Inze D, De Veylder L. 2004. The plant-specific cyclin-dependent kinase CDKB1;1 and transcription factor E2Fa-DPa control the balance of mitotically dividing and endoreduplicating cells in Arabidopsis. Plant Cell 16: 2683-2692.

Boudolf V, Lammens T, Boruc J, Van Leene J, Van Den Daele H, Maes S, Van Isterdael G, Russinova E, Kondorosi E, Witters E, et al. 2009. CDKB1;1 forms a functional complex with CYCA2;3 to suppress endocycle onset. Plant Physiol 150: 1482-1493.

Britton JS, Edgar BA. 1998. Environmental control of the cell cycle in Drosophila: Nutrition activates mitotic and endoreplicative cells by distinct mechanisms. Development 125: 2149-2158.

Britton JS, Lockwood WK, Li L, Cohen SM, Edgar BA. 2002. Drosophila's insulin/PI3-kinase pathway coordinates cellular metabolism with nutritional conditions. Dev Cell 2: 239-249.

Calvi BR, Spradling AC. 1999. Chorion gene amplification in Drosophila: A model for metazoan origins of DNA replication and S-phase control. Methods 18: 407-417.

Calvi BR, Lilly MA, Spradling AC. 1998. Cell cycle control of chorion gene amplification. Genes \& Dev 12: 734-744.

Castellano MM, del Pozo JC, Ramirez-Parra E, Brown S, Gutierrez C. 2001. Expression and stability of Arabidopsis CDC6 are associated with endoreplication. Plant Cell 13: 2671-2686.

Cebolla A, Vinardell JM, Kiss E, Olah B, Roudier F, Kondorosi A, Kondorosi E. 1999. The mitotic inhibitor ccs52 is required for endoreduplication and ploidy-dependent cell enlargement in plants. $E M B O J$ 18: 4476-4484.

Claycomb JM, Benasutti M, Bosco G, Fenger DD, Orr-Weaver TL. 2004. Gene amplification as a developmental strategy: Isolation of two developmental amplicons in Drosophila. Dev Cell 6: 145-155.

Collett CE, Harberd NP, Leyser O. 2000. Hormonal interactions in the control of Arabidopsis hypocotyl elongation. Plant Physiol 124: 553-562.

Cookson SI, Radziejwoski A, Granier C. 2006. Cell and leaf size plasticity in Arabidopsis: What is the role of endoreduplication? Plant Cell Environ 29: 1273-1283.

Coverley D, Laman H, Laskey RA. 2002. Distinct roles for cyclins $\mathrm{E}$ and A during DNA replication complex assembly and activation. Nat Cell Biol 4: 523-528.

Cross JC. 2000. Genetic insights into trophoblast differentiation and placental morphogenesis. Semin Cell Dev Biol 11: 105-113.
Cross, JC. 2005. How to make a placenta: Mechanisms of trophoblast cell differentiation in mice-A review. Placenta 26: S3-S9. doi: 10.1016/j.placenta.2005.01.015.

Cross JC, Hemberger M, Lu Y, Nozaki T, Whiteley K, Masutani M, Adamson SL. 2002. Trophoblast functions, angiogenesis and remodeling of the maternal vasculature in the placenta. Mol Cell Endocrinol 187: 207-212.

Datta NS, Williams JL, Caldwell J, Curry AM, Ashcraft EK, Long MW. 1996. Novel alterations in CDK1/cyclin B1 kinase complex formation occur during the acquisition of a polyploid DNA content. Mol Biol Cell 7: 209-223.

DeGregori J, Johnson DG. 2006. Distinct and overlapping roles for E2F family members in transcription, proliferation and apoptosis. Curr Mol Med 6: 739-748.

Dej KJ, Spradling AC. 1999. The endocycle controls nurse cell polytene chromosome structure during Drosophila oogenesis. Development 126: 293-303.

del Pozo JC, Diaz-Trivino S, Cisneros N, Gutierrez C. 2006. The balance between cell division and endoreplication depends on E2FC-DPB, transcription factors regulated by the ubiquitin-SCFSKP2A pathway in Arabidopsis. Plant Cell 18: 2224-2235

Deng WM, Althauser C, Ruohola-Baker H. 2001. Notch-Delta signaling induces a transition from mitotic cell cycle to endocycle in Drosophila follicle cells. Development 128: 4737-4746.

de Nooij JC, Graber KH, Hariharan IK. 2000. Expression of the cyclin-dependent kinase inhibitor Dacapo is regulated by cyclin E. Mech Dev 97: 73-83.

Diaz-Trivino S, del Mar Castellano M, de la Paz Sanchez M, Ramirez-Parra E, Desvoyes B, Gutierrez C. 2005. The genes encoding Arabidopsis ORC subunits are E2F targets and the two ORC1 genes are differently expressed in proliferating and endoreplicating cells. Nucleic Acids Res 33: 5404-5414.

Dimova DK, Dyson NJ. 2005. The E2F transcriptional network: Old acquaintances with new faces. Oncogene 24: 2810-2826.

Drachman JG, Millett KM, Kaushansky K. 1999. Thrombopoietin signal transduction requires functional JAK2, not TYK2. J Biol Chem 274: 13480-13484.

$\mathrm{Du}$ W. 2000. Suppression of the rbf null mutants by a de2f1 allele that lacks transactivation domain. Development 127: 367-379.

$\mathrm{Du}$ W, Dyson N. 1999. The role of RBF in the introduction of G1 regulation during Drosophila embryogenesis. EMBO I 18: 916-925.

Du W, Vidal M, Xie JE, Dyson N. 1996. RBF, a novel RB-related gene that regulates E2F activity and interacts with cyclin E in Drosophila. Genes \& Dev 10: 1206-1218.

Duncan AW, Hickey RD, Paulk NK, Culberson AJ, Olson SB, Finegold MJ, Grompe M. 2009. Ploidy reductions in murine fusion-derived hepatocytes. PLoS Genet 5: e1000385. doi: 10.1371/journal.pgen.1000385.

Duronio RJ, O'Farrell PH. 1995. Developmental control of the G1 to $\mathrm{S}$ transition in Drosophila: Cyclin Eis a limiting downstream target of E2F. Genes \& Dev 9: 1456-1468.

Duronio RJ, O'Farrell PH, Xie JE, Brook A, Dyson N. 1995. The transcription factor E2F is required for $S$ phase during Drosophila embryogenesis. Genes \& Dev 9: 1445-1455.

Duronio RJ, Bonnette PC, O'Farrell PH. 1998. Mutations of the Drosophila dDP, dE2F, and cyclin E genes reveal distinct roles for the E2F-DP transcription factor and cyclin E during the G1-S transition. Mol Cell Biol 18: 141-151.

Ebbe S. 1976. Biology of megakaryocytes. Prog Hemost Thromb 3: 211-229.

Edgar BA, Nijhout HF. 2004. Growth and cell cycle control in Drosophila. In Cell growth: Control of cell size (eds. M. Raff, 
et al.), pp. 23-83. Cold Spring Harbor Laboratory Press, Cold Spring Harbor, NY.

Edgar BA, Orr-Weaver TL. 2001. Endoreplication cell cycles: More for less. Cell 105: 297-306.

Eigsti OJ. 1938. A cytological study of colchicine effects in the induction of polyploidy in plants. Proc Natl Acad Sci 24: 5663.

Engelen-Eigles G, Jones RJ, Phillips RL. 2001. DNA endoreduplication in maize endosperm cells is reduced by high temperature during the mitotic phase. Crop Sci 41: 1114-1121.

Erenpreisa J, Kalejs M, Cragg MS. 2005a. Mitotic catastrophe and endomitosis in tumour cells: An evolutionary key to a molecular solution. Cell Biol Int 29: 1012-1018.

Erenpreisa J, Kalejs M, Ianzini F, Kosmacek EA, Mackey MA, Emzinsh D, Cragg MS, Ivanov A, Illidge TM. 2005b. Segregation of genomes in polyploid tumour cells following mitotic catastrophe. Cell Biol Int 29: 1005-1011.

Erenpreisa J, Cragg MS, Salmina K, Hausmann M, Scherthan H. 2009. The role of meiotic cohesin REC8 in chromosome segregation in $\gamma$ irradiation-induced endopolyploid tumour cells. Exp Cell Res 315: 2593-2603.

Finkin S, Aylon Y, Anzi S, Oren M, Shaulian E. 2008. Fbw7 regulates the activity of endoreduplication mediators and the p53 pathway to prevent drug-induced polyploidy. Oncogene 27: 4411-4421.

Flemming AJ, Shen ZZ, Cunha A, Emmons SW, Leroi AM. 2000. Somatic polyploidization and cellular proliferation drive body size evolution in nematodes. Proc Natl Acad Sci 97: 5285-5290.

Follette PJ, Duronio RJ, O'Farrell PH. 1998. Fluctuations in cyclin E levels are required for multiple rounds of endocycle S phase in Drosophila. Curr Biol 8: 235-238.

Frolov MV, Huen DS, Stevaux O, Dimova D, Balczarek-Strang K, Elsdon M, Dyson NJ. 2001. Functional antagonism between E2F family members. Genes \& Dev 15: 2146-2160.

Funk-Keenan J, Haire F, Woolard S, Atchley WR. 2008. Hepatic endopolyploidy as a cellular consequence of age-specific selection for rate of development in mice. I Exp Zoolog $B$ Mol Dev Evol 310: 385-397.

Fuse N, Hirose S, Hayashi S. 1994. Diploidy of Drosophila imaginal cells is maintained by a transcriptional repressor encoded by escargot. Genes \& Dev 8: 2270-2281.

Galbraith DW, Harkins KR, Knapp S. 1991. Systemic endopolyploidy in Arabidopsis thaliana. Plant Physiol 96: 985-989.

Gandarillas A, Davies D, Blanchard JM. 2000. Normal and c-Myc-promoted human keratinocyte differentiation both occur via a novel cell cycle involving cellular growth and endoreplication. Oncogene 19: 3278-3289.

Garcia P, Cales C. 1996. Endoreplication in megakaryoblastic cell lines is accompanied by sustained expression of G1/S cyclins and downregulation of cdc25C. Oncogene 13: 695-703.

Garcia P, Frampton J, Ballester A, Cales C. 2000. Ectopic expression of cyclin $\mathrm{E}$ allows non-endomitotic megakaryoblastic K562 cells to establish re-replication cycles. Oncogene 19: 1820-1833.

Garcia-Higuera I, Manchado E, Dubus P, Canamero M, Mendez J, Moreno S, Malumbres M. 2008. Genomic stability and tumour suppression by the APC/C cofactor Cdh1. Nat Cell Biol 10: 802-811.

Gendreau E, Hofte H, Grandjean O, Brown S, Traas J. 1998. Phytochrome controls the number of endoreduplication cycles in the Arabidopsis thaliana hypocotyl. Plant I 13: 221-230.

Gendreau E, Orbovic V, Hofte H, Traas J. 1999. Gibberellin and ethylene control endoreduplication levels in the Arabidopsis thaliana hypocotyl. Planta 209: 513-516.
Geng Y, Yu Q, Sicinska E, Das M, Schneider JE, Bhattacharya S, Rideout WM, Bronson RT, Gardner H, Sicinski P. 2003. Cyclin E ablation in the mouse. Cell 114: 431-443.

Gilbert SF. 2000. Developmental biology. Sinauer Associates, Sunderland, MA.

Gonzalez MA, Tachibana KE, Adams DJ, van der Weyden L, Hemberger M, Coleman N, Bradley A, Laskey RA. 2006. Geminin is essential to prevent endoreduplication and to form pluripotent cells during mammalian development. Genes \& Dev 20: 1880-1884.

Gordon WR, Arnett KL, Blacklow SC. 2008. The molecular logic of Notch signaling - a structural and biochemical perspective. J Cell Sci 121: 3109-3119.

Grafi G, Larkins BA. 1995. Endoreduplication in maize endosperm: Involvement of $\mathrm{M}$ phase-promoting factor inhibition and induction of S phase-related kinases. Science 269: 12621264.

Gurney AL, Carver-Moore K, de Sauvage FJ, Moore MW. 1994. Thrombocytopenia in c-mpl-deficient mice. Science 265: $1445-1447$.

Hara K, Nakayama KI, Nakayama K. 2006. Geminin is essential for the development of preimplantation mouse embryos. Genes Cells 11: 1281-1293.

Hattori N, Davies TC, Anson-Cartwright L, Cross JC. 2000. Periodic expression of the cyclin-dependent kinase inhibitor p57(Kip2) in trophoblast giant cells defines a G2-like gap phase of the endocycle. Mol Biol Cell 11: 1037-1045.

Havens CG, Walter JC. 2009. Docking of a specialized PIP Box onto chromatin-bound PCNA creates a degron for the ubiquitin ligase CRL4Cdt2. Mol Cell 35: 93-104.

Hayashi S. 1996. A Cdc2 dependent checkpoint maintains diploidy in Drosophila. Development 122: 1051-1058.

Hayashi S, Hirose S, Metcalfe T, Shirras AD. 1993. Control of imaginal cell development by the escargot gene of Drosophila. Development 118: 105-115.

Hedgecock EM, White JG. 1985. Polyploid tissues in the nematode Caenorhabditis elegans. Dev Biol 107: 128-133.

Hemann MT, Rudolph KL, Strong MA, DePinho RA, Chin L, Greider CW. 2001. Telomere dysfunction triggers developmentally regulated germ cell apoptosis. Mol Biol Cell 12: 2023-2030.

Hendzel MJ, Wei Y, Mancini MA, Van Hooser A, Ranalli T, Brinkley BR, Bazett-Jones DP, Allis CD. 1997. Mitosisspecific phosphorylation of histone $\mathrm{H} 3$ initiates primarily within pericentromeric heterochromatin during G2 and spreads in an ordered fashion coincident with mitotic chromosome condensation. Chromosoma 106: 348-360.

Herbig U, Jobling WA, Chen BP, Chen DJ, Sedivy JM. 2004. Telomere shortening triggers senescence of human cells through a pathway involving ATM, p53, and p21(CIP1), but not p16(INK4a). Mol Cell 14: 501-513.

Higa LA, Banks D, Wu M, Kobayashi R, Sun H, Zhang H. 2006. L2DTL/CDT2 interacts with the CUL4/DDB1 complex and PCNA and regulates CDT1 proteolysis in response to DNA damage. Cell Cycle 5: 1675-1680.

Hong A, Narbonne-Reveau K, Riesgo-Escovar J, Fu H, Aladjem MI, Lilly MA. 2007. The cyclin-dependent kinase inhibitor Dacapo promotes replication licensing during Drosophila endocycles. EMBO J 26: 2071-2082.

$\mathrm{Hu}$ J, Xiong Y. 2006. An evolutionarily conserved function of proliferating cell nuclear antigen for Cdt1 degradation by the Cul4-Ddb1 ubiquitin ligase in response to DNA damage. I Biol Chem 281: 3753-3756.

Hulskamp M, Schnittger A, Folkers U. 1999. Pattern formation and cell differentiation: Trichomes in Arabidopsis as a genetic model system. Int Rev Cytol 186: 147-178. 
Ianzini F, Kosmacek EA, Nelson ES, Napoli E, Erenpreisa J, Kalejs M, Mackey MA. 2009. Activation of meiosis-specific genes is associated with depolyploidization of human tumor cells following radiation-induced mitotic catastrophe. Cancer Res 69: 2296-2304.

Ihara K, Ishii E, Eguchi M, Takada H, Suminoe A, Good RA, Hara T. 1999. Identification of mutations in the c-mpl gene in congenital amegakaryocytic thrombocytopenia. Proc Natl Acad Sci 96: 3132-3136.

Imai KK, Ohashi Y, Tsuge T, Yoshizumi T, Matsui M, Oka A, Aoyama T. 2006. The A-type cyclin CYCA2;3 is a key regulator of ploidy levels in Arabidopsis endoreduplication. Plant Cell 18: 382-396.

Inze D, De Veylder L. 2006. Cell cycle regulation in plant development. Annu Rev Genet 40: 77-105.

Ivanov A, Cragg MS, Erenpreisa J, Emzinsh D, Lukman H, Illidge TM. 2003. Endopolyploid cells produced after severe genotoxic damage have the potential to repair DNA double strand breaks. J Cell Sci 116: 4095-4106.

Jackson PK, Chevalier S, Philippe M, Kirschner MW. 1995. Early events in DNA replication require cyclin $\mathrm{E}$ and are blocked by p21CIP1. J Cell Biol 130: 755-769.

Jakoby M, Schnittger A. 2004. Cell cycle and differentiation. Curr Opin Plant Biol 7: 661-669.

Jordan KC, Schaeffer V, Fischer KA, Gray EE, Ruohola-Baker H. 2006. Notch signaling through tramtrack bypasses the mitosis promoting activity of the JNK pathway in the mitoticto-endocycle transition of Drosophila follicle cells. BMC Dev Biol 6: 16. doi: 10.1186/1471-213X-6-16.

Joubes J, Chevalier C. 2000. Endoreduplication in higher plants. Plant Mol Biol 43: 735-745.

Kaushansky K. 1995. Thrombopoietin: Basic biology, clinical promise. Int I Hematol 62: 7-15.

Kaushansky K. 2005. The molecular mechanisms that control thrombopoiesis. J Clin Invest 115: 3339-3347.

Kaushansky K. 2008. Historical review: Megakaryopoiesis and thrombopoiesis. Blood 111: 981-986.

Kaushansky K, Lok S, Holly RD, Broudy VC, Lin N, Bailey MC, Forstrom JW, Buddle MM, Oort PJ, Hagen FS, et al. 1994. Promotion of megakaryocyte progenitor expansion and differentiation by the $\mathrm{c}-\mathrm{Mpl}$ ligand thrombopoietin. Nature 369: $568-571$.

Kikuchi J, Furukawa Y, Iwase S, Terui Y, Nakamura M, Kitagawa S, Kitagawa M, Komatsu N, Miura Y. 1997. Polyploidization and functional maturation are two distinct processes during megakaryocytic differentiation: Involvement of cyclin-dependent kinase inhibitor p21 in polyploidization. Blood 89: 3980-3990.

Klapholz B, Dietrich BH, Schaffner C, Heredia F, Quivy JP, Almouzni G, Dostatni N. 2009. CAF-1 is required for efficient replication of euchromatic DNA in Drosophila larval endocycling cells. Chromosoma 118: 235-248.

Knoblich JA, Sauer K, Jones L, Richardson H, Saint R, Lehner CF. 1994. Cyclin E controls S phase progression and its down-regulation during Drosophila embryogenesis is required for the arrest of cell proliferation. Cell 77: 107-120.

Koepp DM, Schaefer LK, Ye X, Keyomarsi K, Chu C, Harper JW, Elledge SJ. 2001. Phosphorylation-dependent ubiquitination of cyclin E by the SCFFbw7 ubiquitin ligase. Science 294: $173-177$.

Kohn MJ, Bronson RT, Harlow E, Dyson NJ, Yamasaki L. 2003. Dp1 is required for extra-embryonic development. Development 130: 1295-1305.

Kondorosi E, Kondorosi A. 2004. Endoreduplication and activation of the anaphase-promoting complex during symbiotic cell development. FEBS Lett 567: 152-157.
Kondorosi E, Roudier F, Gendreau E. 2000. Plant cell-size control: Growing by ploidy? Curr Opin Plant Biol 3: 488-492.

Labib K, Gambus A. 2007. A key role for the GINS complex at DNA replication forks. Trends Cell Biol 17: 271-278.

Lammens T, Boudolf V, Kheibarshekan L, Zalmas LP, Gaamouche T, Maes S, Vanstraelen M, Kondorosi E, La Thangue NB, Govaerts W, et al. 2008. Atypical E2F activity restrains APC/CCCS52A2 function obligatory for endocycle onset. Proc Natl Acad Sci 105: 14721-14726.

Lammens T, Li J, Leone G, De Veylder L. 2009. Atypical E2Fs: New players in the E2F transcription factor family. Trends Cell Biol 19: 111-118.

Lane ME, Elend M, Heidmann D, Herr A, Marzodko S, Herzig A, Lehner CF. 2000. A screen for modifiers of cyclin E function in Drosophila melanogaster identifies Cdk2 mutations, revealing the insignificance of putative phosphorylation sites in Cdk2. Genetics 155: 233-244.

Lazzerini Denchi E, Celli G, de Lange T. 2006. Hepatocytes with extensive telomere deprotection and fusion remain viable and regenerate liver mass through endoreduplication. Genes \& Dev 20: 2648-2653.

Leach TJ, Chotkowski HL, Wotring MG, Dilwith RL, Glaser RL. 2000. Replication of heterochromatin and structure of polytene chromosomes. Mol Cell Biol 20: 6308-6316.

Leiva-Neto JT, Grafi G, Sabelli PA, Dante RA, Woo YM, Maddock S, Gordon-Kamm WJ, Larkins BA. 2004. A dominant negative mutant of cyclin-dependent kinase A reduces endoreduplication but not cell size or gene expression in maize endosperm. Plant Cell 16: 1854-1869.

Lilly MA, Duronio RJ. 2005. New insights into cell cycle control from the Drosophila endocycle. Oncogene 24: 2765-2775.

Lilly MA, Spradling AC. 1996. The Drosophila endocycle is controlled by Cyclin E and lacks a checkpoint ensuring S-phase completion. Genes \& Dev 10: 2514-2526.

Lopez-Schier H, St Johnston D. 2001. Delta signaling from the germ line controls the proliferation and differentiation of the somatic follicle cells during Drosophila oogenesis. Genes \& Dev 15: 1393-1405.

Lozano E, Saez AG, Flemming AJ, Cunha A, Leroi AM. 2006. Regulation of growth by ploidy in Caenorhabditis elegans. Curr Biol 16: 493-498.

Luoh SM, Stefanich E, Solar G, Steinmetz H, Lipari T, Pestina TI, Jackson CW, de Sauvage FJ. 2000. Role of the distal half of the c-Mpl intracellular domain in control of platelet production by thrombopoietin in vivo. Mol Cell Biol 20: 507-515.

Maines JZ, Stevens LM, Tong X, Stein D. 2004. Drosophila $\mathrm{dMyc}$ is required for ovary cell growth and endoreplication. Development 131: 775-786.

Martindill DM, Riley PR. 2008. Cell cycle switch to endocycle: The nucleolus lends a hand. Cell Cycle 7: 17-23.

Matsumura I, Tanaka H, Kawasaki A, Odajima J, Daino H, Hashimoto K, Wakao H, Nakajima K, Kato T, Miyazaki H, et al. 2000. Increased D-type cyclin expression together with decreased cdc2 activity confers megakaryocytic differentiation of a human thrombopoietin-dependent hematopoietic cell line. J Biol Chem 275: 5553-5559.

McGarry TJ, Kirschner MW. 1998. Geminin, an inhibitor of DNA replication, is degraded during mitosis. Cell 93: 10431053.

Meckert PC, Rivello HG, Vigliano C, Gonzalez P, Favaloro R, Laguens R. 2005. Endomitosis and polyploidization of myocardial cells in the periphery of human acute myocardial infarction. Cardiovasc Res 67: 116-123.

Mehrotra S, Maqbool SB, Kolpakas A, Murnen K, Calvi BR. 2008. Endocycling cells do not apoptose in response to DNA rereplication genotoxic stress. Genes \& Dev 22: 3158-3171. 
Menand B, Yi K, Jouannic S, Hoffmann L, Ryan E, Linstead P, Schaefer DG, Dolan L. 2007. An ancient mechanism controls the development of cells with a rooting function in land plants. Science 316: 1477-1480.

Mercher T, Cornejo MG, Sears C, Kindler T, Moore SA, Maillard I, Pear WS, Aster JC, Gilliland DG. 2008. Notch signaling specifies megakaryocyte development from hematopoietic stem cells. Cell Stem Cell 3: 314-326.

Micchelli CA, Perrimon N. 2006. Evidence that stem cells reside in the adult Drosophila midgut epithelium. Nature 439: 475-479.

Moberg KH, Bell DW, Wahrer DC, Haber DA, Hariharan IK. 2001. Archipelago regulates Cyclin E levels in Drosophila and is mutated in human cancer cell lines. Nature 413: 311316.

Morgan DO. 2007. The cell cycle: Principles of control. New Science Press, London.

Murone M, Carpenter DA, de Sauvage FJ. 1998. Hematopoietic deficiencies in c-mpl and TPO knockout mice. Stem Cells 16: $1-6$.

Nagata Y, Muro Y, Todokoro K. 1997. Thrombopoietin-induced polyploidization of bone marrow megakaryocytes is due to a unique regulatory mechanism in late mitosis. I Cell Biol 139: 449-457.

Nakayama H, Liu Y, Stifani S, Cross JC. 1997. Developmental restriction of Mash-2 expression in trophoblast correlates with potential activation of the notch-2 pathway. Dev Genet 21: 21-30.

Nakayama H, Scott IC, Cross JC. 1998. The transition to endoreduplication in trophoblast giant cells is regulated by the mSNA zinc finger transcription factor. Dev Biol 199: 150-163.

Narbonne-Reveau K, Senger S, Pal M, Herr A, Richardson HE, Asano M, Deak P, Lilly MA. 2008. APC/CFzr/Cdh1 promotes cell cycle progression during the Drosophila endocycle. Development 135: 1451-1461.

Nurden AT. 2005. Qualitative disorders of platelets and megakaryocytes. J Thromb Haemost 3: 1773-1782.

Ohlstein B, Spradling A. 2006. The adult Drosophila posterior midgut is maintained by pluripotent stem cells. Nature 439: 470-474.

Pang L, Weiss MJ, Poncz M. 2005. Megakaryocyte biology and related disorders. J Clin Invest 115: 3332-3338.

Parisi T, Beck AR, Rougier N, McNeil T, Lucian L, Werb Z, Amati B. 2003. Cyclins E1 and E2 are required for endoreplication in placental trophoblast giant cells. $E M B O J \mathbf{2 2}$ 4794-4803.

Park SY, Asano M. 2008. The origin recognition complex is dispensable for endoreplication in Drosophila. Proc Natl Acad Sci 105: 12343-12348.

Park JA, Ahn JW, Kim YK, Kim SJ, Kim JK, Kim WT, Pai HS. 2005. Retinoblastoma protein regulates cell proliferation, differentiation, and endoreduplication in plants. Plant $J$ 42: 153-163.

Pflumm MF, Botchan MR. 2001. Orc mutants arrest in metaphase with abnormally condensed chromosomes. Development 128: 1697-1707.

Pierce SB, Yost C, Britton JS, Loo LW, Flynn EM, Edgar BA, Eisenman RN. 2004. dMyc is required for larval growth and endoreplication in Drosophila. Development 131: 23172327.

Pinto S, Quintana DG, Smith P, Mihalek RM, Hou ZH, Boynton S, Jones CJ, Hendricks M, Velinzon K, Wohlschlegel JA, et al. 1999. latheo encodes a subunit of the origin recognition complex and disrupts neuronal proliferation and adult olfactory memory when mutant. Neuron 23: 45-54.
Poellinger L, Lendahl U. 2008. Modulating Notch signaling by pathway-intrinsic and pathway-extrinsic mechanisms. Curr Opin Genet Dev 18: 449-454.

Prieur-Carrillo G, Chu K, Lindqvist J, Dewey WC. 2003. Computerized video time-lapse (CVTL) analysis of the fate of giant cells produced by X-irradiating EJ30 human bladder carcinoma cells. Radiat Res 159: 705-712.

Puig PE, Guilly MN, Bouchot A, Droin N, Cathelin D, Bouyer F, Favier L, Ghiringhelli F, Kroemer G, Solary E, et al. 2008. Tumor cells can escape DNA-damaging cisplatin through DNA endoreduplication and reversible polyploidy. Cell Biol Int 32: 1031-1043.

Rasheva VI, Knight D, Bozko P, Marsh K, Frolov MV. 2006. Specific role of the SR protein splicing factor B52 in cell cycle control in Drosophila. Mol Cell Biol 26: 3468-3477.

Ravid K, Lu J, Zimmet JM, Jones MR. 2002. Roads to polyploidy: The megakaryocyte example. J Cell Physiol 190: 7-20.

Rojnuckarin P, Drachman JG, Kaushansky K. 1999. Thrombopoietin-induced activation of the mitogen-activated protein kinase (MAPK) pathway in normal megakaryocytes: Role in endomitosis. Blood 94: 1273-1282.

Rossant J, Cross JC. 2001. Placental development: lessons from mouse mutants. Nat Rev Genet 2: 538-548.

Royzman I, Whittaker AJ, Orr-Weaver TL. 1997. Mutations in Drosophila DP and E2F distinguish G1-S progression from an associated transcriptional program. Genes \& Dev 11: 19992011.

Royzman I, Hayashi-Hagihara A, Dej KJ, Bosco G, Lee JY, OrrWeaver TL. 2002. The E2F cell cycle regulator is required for Drosophila nurse cell DNA replication and apoptosis. Mech Dev 119: 225-237.

Santamaria D, Barriere C, Cerqueira A, Hunt S, Tardy C, Newton K, Caceres JF, Dubus P, Malumbres M, Barbacid M. 2007. Cdk1 is sufficient to drive the mammalian cell cycle. Nature 448: 811-815.

Sauer K, Knoblich JA, Richardson H, Lehner CF. 1995. Distinct modes of cyclin $\mathrm{E} / \mathrm{cdc} 2 \mathrm{c}$ kinase regulation and S-phase control in mitotic and endoreduplication cycles of Drosophila embryogenesis. Genes \& Dev 9: 1327-1339.

Schaeffer V, Althauser C, Shcherbata HR, Deng WM, RuoholaBaker H. 2004. Notch-dependent Fizzy-related/Hec1/Cdh1 expression is required for the mitotic-to-endocycle transition in Drosophila follicle cells. Curr Biol 14: 630-636.

Schweizer L, Yerk-Davis GL, Phillips RL, Srienc F, Jones RJ. 1995. Dynamics of maize endosperm development and DNA endoreduplication. Proc Natl Acad Sci 92: 70707074.

Sclafani RA, Holzen TM. 2007. Cell cycle regulation of DNA replication. Annu Rev Genet 41: 237-280.

Senga T, Sivaprasad U, Zhu W, Park JH, Arias EE, Walter JC, Dutta A. 2006. PCNA is a cofactor for Cdt1 degradation by CUL4/DDB1-mediated N-terminal ubiquitination. I Biol Chem 281: 6246-6252.

Shcherbata HR, Althauser C, Findley SD, Ruohola-Baker H. 2004. The mitotic-to-endocycle switch in Drosophila follicle cells is executed by Notch-dependent regulation of G1/S, G2/M and M/G1 cell-cycle transitions. Development 131: 3169-3181.

Shibutani ST, de la Cruz AF, Tran V, Turbyfill WJ 3rd, Reis T, Edgar BA, Duronio RJ. 2008. Intrinsic negative cell cycle regulation provided by PIP box- and Cul4Cdt2mediated destruction of E2f1 during S phase. Dev Cell 15: 890-900.

Sigrist SJ, Lehner CF. 1997. Drosophila fizzy-related downregulates mitotic cyclins and is required for cell proliferation arrest and entry into endocycles. Cell 90: 671-681. 
Smith AV, Orr-Weaver TL. 1991. The regulation of the cell cycle during Drosophila embryogenesis: The transition to polyteny. Development 112: 997-1008.

Solar GP, Kerr WG, Zeigler FC, Hess D, Donahue C, de Sauvage FJ, Eaton DL. 1998. Role of c-mpl in early hematopoiesis. Blood 92: 4-10.

Storchova Z, Pellman D. 2004. From polyploidy to aneuploidy, genome instability and cancer. Nat Rev Mol Cell Biol 5: 45-54.

Strohmaier H, Spruck CH, Kaiser P, Won KA, Sangfelt O, Reed SI. 2001. Human F-box protein hCdc4 targets cyclin E for proteolysis and is mutated in a breast cancer cell line. Nature 413: 316-322.

Su TT, O'Farrell PH. 1998. Chromosome association of minichromosome maintenance proteins in Drosophila endoreplication cycles. J Cell Biol 140: 451-460.

Sugimoto-Shirasu K, Roberts K. 2003. 'Big it up': Endoreduplication and cell-size control in plants. Curr Opin Plant Biol 6: 544-553.

Sun J, Deng WM. 2005. Notch-dependent downregulation of the homeodomain gene cut is required for the mitotic cycle/ endocycle switch and cell differentiation in Drosophila follicle cells. Development 132: 4299-4308.

Sun J, Deng WM. 2007. Hindsight mediates the role of notch in suppressing hedgehog signaling and cell proliferation. Dev Cell 12: 431-442.

Sun J, Smith L, Armento A, Deng WM. 2008. Regulation of the endocycle/gene amplification switch by Notch and ecdysone signaling. J Cell Biol 182: 885-896.

Swain SM, Tseng TS, Thornton TM, Gopalraj M, Olszewski NE. 2002. SPINDLY is a nuclear-localized repressor of gibberellin signal transduction expressed throughout the plant. Plant Physiol 129: 605-615.

Szuplewski S, Sandmann T, Hietakangas V, Cohen SM. 2009. Drosophila Minus is required for cell proliferation and influences Cyclin E turnover. Genes \& Dev 23: 1998-2003.

Talora C, Campese AF, Bellavia D, Felli MP, Vacca A, Gulino A, Screpanti I. 2008.. Notch signaling and diseases: An evolutionary journey from a simple beginning to complex outcomes. Biochim Biophys Acta 1782: 489-497.

Tateishi K, Omata M, Tanaka K, Chiba T. 2001. The NEDD8 system is essential for cell cycle progression and morphogenetic pathway in mice. J Cell Biol 155: 571-579.

Tetzlaff MT, Yu W, Li M, Zhang P, Finegold M, Mahon K, Harper JW, Schwartz RJ, Elledge SJ. 2004. Defective cardiovascular development and elevated cyclin $\mathrm{E}$ and Notch proteins in mice lacking the Fbw7 F-box protein. Proc Natl Acad Sci 101: 3338-3345.

Tomer A, Friese P, Conklin R, Bales W, Archer L, Harker LA, Burstein SA. 1989. Flow cytometric analysis of megakaryocytes from patients with abnormal platelet counts. Blood 74: 594-601.

Tower J. 2004. Developmental gene amplification and origin regulation. Annu Rev Genet 38: 273-304.

Ullah Z, Kohn MJ, Yagi R, Vassilev LT, DePamphilis ML. 2008. Differentiation of trophoblast stem cells into giant cells is triggered by $\mathrm{p} 57 / \mathrm{Kip} 2$ inhibition of CDK1 activity. Genes \& Dev 22: 3024-3036.

Ullah Z, Lee CY, Lilly MA, DePamphilis ML. 2009. Developmentally programmed endoreduplication in animals. Cell Cycle 8: 1501-1509.

van den Heuvel S, Dyson NJ. 2008. Conserved functions of the pRB and E2F families. Nat Rev Mol Cell Biol 9: 713-724.

Vilaboa N, Bermejo R, Martinez P, Bornstein R, Cales C. 2004. A novel E2 box-GATA element modulates Cdc6 transcription during human cells polyploidization. Nucleic Acids Res 32: 6454-6467.
Vitrat N, Cohen-Solal K, Pique C, Le Couedic JP, Norol F, Larsen AK, Katz A, Vainchenker W, Debili N. 1998. Endomitosis of human megakaryocytes are due to abortive mitosis. Blood 91: 3711-3723.

Vlieghe K, Boudolf V, Beemster GT, Maes S, Magyar Z, Atanassova A, de Almeida Engler J, De Groodt R, Inze D, De Veylder L. 2005. The DP-E2F-like gene DEL1 controls the endocycle in Arabidopsis thaliana. Curr Biol 15: 59-63.

Walen KH. 2002. The origin of transformed cells. studies of spontaneous and induced cell transformation in cell cultures from marsupials, a snail, and human amniocytes. Cancer Genet Cytogenet 133: 45-54.

Walen KH. 2007a. Bipolar genome reductional division of human near-senescent, polyploid fibroblast cells. Cancer Genet Cytogenet 173: 43-50.

Walen KH. 2007b. Origin of diplochromosomal polyploidy in near-senescent fibroblast cultures: Heterochromatin, telomeres and chromosomal instability (CIN). Cell Biol Int 31: $1447-1455$.

Walker JD, Oppenheimer DG, Concienne J, Larkin JC. 2000. SIAMESE, a gene controlling the endoreduplication cell cycle in Arabidopsis thaliana trichomes. Development 127: 3931-3940.

Weigmann K, Cohen SM, Lehner CF. 1997. Cell cycle progression, growth and patterning in imaginal discs despite inhibition of cell division after inactivation of Drosophila Cdc2 kinase. Development 124: 3555-3563.

Weiss A, Herzig A, Jacobs H, Lehner CF. 1998. Continuous Cyclin E expression inhibits progression through endoreduplication cycles in Drosophila. Curr Biol 8: 239-242.

Weng L, Zhu C, Xu J, Du W. 2003. Critical role of active repression by $\mathrm{E} 2 \mathrm{~F}$ and $\mathrm{Rb}$ proteins in endoreplication during Drosophila development. EMBO J 22: 3865-3875.

Wigge PA, Weigel D. 2001. Arabidopsis genome: Life without notch. Curr Biol 11: R112-R114. doi: 10.1016/S09609822(01)00043-4.

Wilson LB. 1925. Microscopic examination of fresh tissue. Ann Surg 81: 863-868.

Wohlschlegel JA, Dwyer BT, Dhar SK, Cvetic C, Walter JC, Dutta A. 2000. Inhibition of eukaryotic DNA replication by geminin binding to Cdt1. Science 290: 2309-2312.

Yeung EC, Meinke DW. 1993. Embryogenesis in angiosperms: Development of the suspensor. Plant Cell 5: 1371-1381.

Zachariae W, Schwab M, Nasmyth K, Seufert W. 1998. Control of cyclin ubiquitination by CDK-regulated binding of Hct 1 to the anaphase promoting complex. Science 282: 1721-1724.

Zhang Y, Kalderon D. 2000. Regulation of cell proliferation and patterning in Drosophila oogenesis by Hedgehog signaling. Development 127: 2165-2176.

Zhang Y, Wang Z, Ravid K. 1996. The cell cycle in polyploid megakaryocytes is associated with reduced activity of cyclin B1-dependent cdc2 kinase. J Biol Chem 271: 4266-4272.

Zhong W, Feng H, Santiago FE, Kipreos ET. 2003. CUL-4 ubiquitin ligase maintains genome stability by restraining DNA-replication licensing. Nature 423: 885-889.

Zielke N, Querings S, Rottig C, Lehner C, Sprenger F. 2008. The anaphase-promoting complex/cyclosome (APC/C) is required for rereplication control in endoreplication cycles. Genes \& Dev 22: 1690-1703.

Zybina TG, Zybina EV. 2005. Cell reproduction and genome multiplication in the proliferative and invasive trophoblast cell populations of mammalian placenta. Cell Biol Int 29: 1071-1083. 


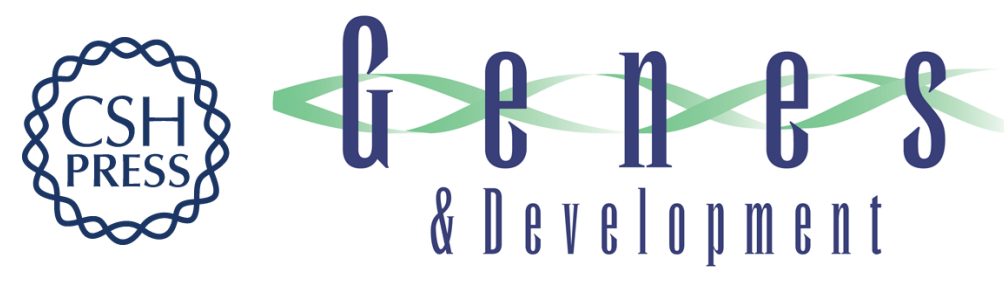

\section{Endoreplication: polyploidy with purpose}

Hyun O. Lee, Jean M. Davidson and Robert J. Duronio

Genes Dev. 2009, 23:

Access the most recent version at doi:10.1101/gad.1829209

References This article cites 198 articles, 93 of which can be accessed free at: http://genesdev.cshlp.org/content/23/21/2461.full.html\#ref-list-1

License

Email Alerting Receive free email alerts when new articles cite this article - sign up in the box at the top Service right corner of the article or click here.

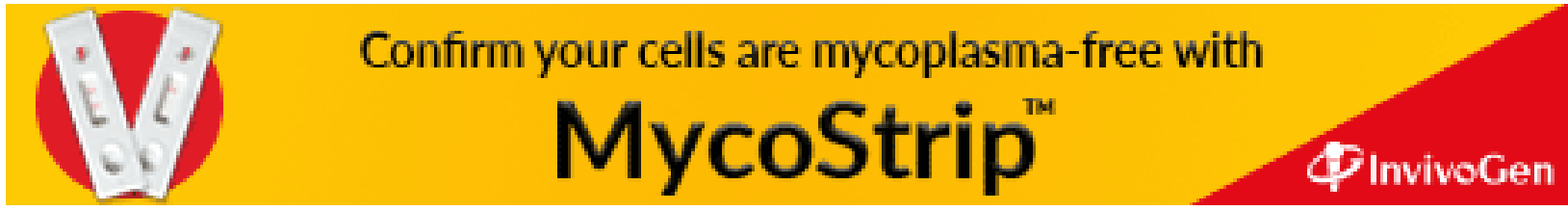

